Supporting Information for

\title{
Negatively Charged Sulfur Quantum Dots for Treatment of Drug-Resistant Pathogenic Bacterial Infections
}

Yi Wang, ${ }^{\dagger}$ Yannan Zhao, ${ }^{\ddagger}$ Jiangling Wu,${ }^{\S}$ Ming Li,${ }^{\ddagger}$ Juan Tan,${ }^{\dagger}$ Wensheng Fu, ${ }^{\dagger}$ Hua Tang,,$* *$ and Pu Zhang ${ }^{\text {t,* }}$

$\dagger$ Engineering Research Center for Biotechnology of Active Substances (Ministry of Education), Chongqing Key Laboratory of Green Synthesis and Applications, College of Chemistry, Chongqing Normal University, Chongqing 401331, P.R. China

* Key Laboratory of Molecular Biology for Infectious Diseases (Ministry of Education), Chongqing Research Center for Pharmaceutical Engineering, College of Pharmacy, Chongqing Medical University, Chongqing 400016, P.R. China

${ }^{\S}$ Department of Clinical Laboratory, University Town Hospital of Chongqing Medical University, Chongqing 401331, China

*To whom correspondence should be addressed. E-mail: zhangpu51@hotmail.com (P. Zhang); tanghua86162003@cqmu.edu.cn (H. Tang) 
Materials and reagents. 9,10-Anthracenediyl-bis(methylene)-dimalonic acid (ABDA) and propidium iodide (PI) were purchased from Sigma-Aldrich (St. Louis, USA). Poly(sodium-4-styrenesulfonate) (PSS), paraformaldehyde, acridine orange (AO), ethidium bromide $(\mathrm{EB})$ and 3,3'-dipropylthiadicarbocyanine iodide $\left[\mathrm{diSC}_{3}(5)\right]$ were purchased from Aladdin Co. Ltd (Shanghai, China). Sulfur powder, hydrogen peroxide $\left(\mathrm{H}_{2} \mathrm{O}_{2}, 30 \%\right.$, v/v), sodium hypochlorite $(\mathrm{NaClO})$, sodium carbonate $\left(\mathrm{Na}_{2} \mathrm{CO}_{3}\right)$, sodium bicarbonate $\left(\mathrm{NaHCO}_{3}\right)$, sodium dihydrogen phosphate $\left(\mathrm{NaH}_{2} \mathrm{PO}_{4}\right)$, glutaraldehyde, crystal violet, methanol and ethanol were purchased from Chengdu Kelong Chemical Reagent Factory (Sichuan, China). Disodium phosphate $\left(\mathrm{Na}_{2} \mathrm{HPO}_{4}\right)$, sodium chloride $(\mathrm{NaCl})$ and potassium chloride $(\mathrm{KCl})$ were purchased from Chuandong Chemical Co. Ltd (Chongqing, China). Sodium hydroxide $(\mathrm{NaOH})$ was purchased from Sinopharm Chemical Reagent Co., Ltd (Shanghai, China). Quinine sulfate (QS) was purchased from Xiya Reagent Co., Ltd (Shandong, China). Luria Bertani (LB) agar/broth were purchased from Sangon Biotech Co., Ltd (Shanghai, China). ATP assay kit was purchased from Beyotime Biotech Co., Ltd (Shanghai, China). Dulbecco's modified eagle medium (DMEM) was purchased from SAIMIKE Biotech Co., Ltd (Chongqing, China). MTS kit was purchased from Promega Biotech Co., Ltd (Beijing, China). Methicillin-resistant Staphylococcus aureus (MRSA, ATCC 43300), Pseudomonas aeruginosa (PAE, ATCC 27853), Enterococcus faecalis (E. faecalis, ATCC 29212), Escherichia coli (E. coli, ATCC 25922), Klebsiella pneumoniae (K. pneumoniae, Clinical wild strains), Acinetobacter baumannii (A. baumannii, Clinical wild strains) were obtained from University-Town Hospital of Chongqing Medical University. Healthy BALB/c mice (6-8 weeks, female) obtained from Laboratory Animal Center of Chongqing Medical University (Chongqing, China) and raised in individual ventilated cages were used to evaluate the in vivo antibacterial activity and toxicity of the materials. All animal procedures were in accordance with the Guidelines for Care and Use of Laboratory Animals that approved by the Ethics Committee of Chongqing Medical University.

Instruments. Morphology and size of the PSS-SNPs and PSS-SQDs were characterized by a transmission electron microscope (TEM, FEI Tecnai G2 F30, USA) and an atomic force 
microscope (AFM, Bruker Dension Icon, USA). Hydrodynamic diameter and zeta potential of the PSS-SQDs were measured by a laser particle size analyzer (Malvern ZEN3600, UK). UV-vis spectra and fluorescence spectra were measured with an UV-2600 spectrophotometer (Shimadzu, Japan) and an LS-55 fluorescence spectrophotometer (PerkinElmer, USA), respectively. X-ray photoelectron spectroscopy (XPS) data of the PSS-SQDs were recorded using an X-ray photoelectron spectrometer (Thermo escalab 250Xi, USA). Fourier transformed infrared (FTIR) spectra were collected by an FTIR-8400S spectrometer (Shimadzu, Japan). Electron paramagnetic resonance (ERP) signal was detected by an electron spin resonance spectrometer (Bruker A300, Germany). The concentrations of PSS-SNPs and PSS-SQDs were measured by an inductively coupled plasma mass spectrometer (ICP-MS, Agilent ICPMS7800, USA). The morphology of bacteria was recorded by a Tecnai G2 F30 transmission electron microscope (TEM, FEI, USA) and an SU8020 scanning electron microscope (SEM, Shimadzu, Japan). Fluorescence imaging of the bacteria was conducted by a confocal laser fluorescence microscope (Nikon A1+R, Japan). A microplate reader (Thermo Scientific Varioskan 3020, USA) was used to measure the absorbance for cytotoxicity evaluation. An incubator shaker (Crystal IS-RSV1, USA) was used to culture the bacteria.

Synthesis of PSS-SQDs. In a standard procedure, sulfur powder (1.5 g), PSS (0.15 g), and $\mathrm{NaOH}(4 \mathrm{~g})$ were added into a round-bottom flask with $50 \mathrm{~mL}$ ultra-pure water and stirred at $70^{\circ} \mathrm{C}$ for $12 \mathrm{~h}$. PSS-stabilized sulfur nanoparticles (PSS-SNPs) were obtained by dialyzing to adjust the $\mathrm{pH}$ to $8 \sim 9$. Then, $1.5 \mathrm{~mL}$ of the PSS-SNPs were mixed with $2 \mathrm{~mL}$ of $8.5 \mathrm{wt} \% \mathrm{H}_{2} \mathrm{O}_{2}$ overnight to generate PSS-SQDs. The concentrations of PSS-SNPs and PSS-SQDs were measured by ICP-MS. For optimization of the synthetic conditions, the amounts of different reactants, temperature and reaction time were systematically studied.

Measurement of fluorescence quantum yield (QY) of PSS-SQDs. Quinine sulfate (QY = $54 \%$ in $0.1 \mathrm{~mol} / \mathrm{L} \mathrm{H}_{2} \mathrm{SO}_{4}$ ) was used as a reference to determine the fluorescence quantum yield of PSS-SQDs, which was calculated according to the following equation: ${ }^{1}$ 


$$
\phi=\phi^{\prime} \times \frac{A^{\prime}}{I^{\prime}} \times \frac{I}{A} \times \frac{n^{2}}{n^{\prime 2}}
$$

where $\phi$ is the QY of the PSS-SQDs, $I$ is the integrated emission intensity of the PSS-SQDs, $n$ is the refractive index of the solvent (water, $n=1.33$ ), and $A$ is the optical density of the PSS-SQDs. The prime symbol (') refers to the referenced dye of quinine sulfate. To minimize reabsorption effects, absorption was always kept below 0.05 at the excitation wavelength.

Bacterial culture. LB broth and LB agar were firstly prepared according to the formula for bacterial culture. The strain was inoculated to the $\mathrm{LB}$ broth, and then cultured in a $37^{\circ} \mathrm{C}$ incubator, with a rotational motion of 220 revolutions per minute (rpm). The bacteria growing in logarithmic phase were determined with a microplate reader. The bacteria grew to $10^{8}$ colony forming units per milliliter $(\mathrm{CFU} / \mathrm{mL})$ when the value of optical density at $600 \mathrm{~nm}$ $\left(\mathrm{OD}_{600}\right)$ increased to 0.5 . The concentration of bacteria used in each experiment is dependent on the experimental condition and test purpose. $^{2}$

Evaluation of antibacterial activity in vitro. MRSA and PAE strains were cultured in LB broth and shake for $2 \mathrm{~h}$ to grow to the logarithmic phase in a $37^{\circ} \mathrm{C}$ incubator with $220 \mathrm{rpm}$, respectively. The bacterial suspension was then diluted to $10^{6} \mathrm{CFU} / \mathrm{mL}$ by PBS buffer $(0.01$ M, pH 7.4). Then, $100 \mu \mathrm{L}$ of bacterial suspension was mixed with $100 \mu \mathrm{L}$ of PBS buffer, PSS, PSS-SNPs, and PSS-SQDs, respectively, and incubated for $20 \mathrm{~min}$ at $37^{\circ} \mathrm{C}$. The final concentration of the above regents was $1.8 \mathrm{mg} / \mathrm{mL} .10 \mu \mathrm{L}$ of each group was spread evenly on the LB agar and cultured overnight in a $37^{\circ} \mathrm{C}$ incubator. The bacterial colonies on the plates were observed and recorded. Besides, $100 \mu \mathrm{L}$ of the above each group was added into $5 \mathrm{~mL}$ of LB broth and cultured overnight in a $37^{\circ} \mathrm{C}$ incubator. The optical density at $\mathrm{OD}_{600}$ of the bacterial suspension was measured by a microplate reader.

Determination of minimal inhibitory concentration (MIC) and antibacterial efficiency. The MIC of PSS-SQDs and PSS-SNPs were determined by the agar plate method. MRSA and PAE strains were cultured in $\mathrm{LB}$ broth to grow to the logarithmic phase in a $37^{\circ} \mathrm{C}$ 
incubator. The bacterial suspension was then diluted to $10^{6} \mathrm{CFU} / \mathrm{mL}$ by PBS buffer $(0.01 \mathrm{M}$, $\mathrm{pH}$ 7.4). Then, $100 \mu \mathrm{L}$ of bacterial suspension was mixed with $100 \mu \mathrm{L}$ of different concentrations of PSS-SQDs and PSS-SNPs, respectively, and incubated for $20 \mathrm{~min}$ at $37^{\circ} \mathrm{C}$. The final concentrations of PSS-SQDs and PSS-SNPs were in the range of $0.5-2.4 \mathrm{mg} / \mathrm{mL}$. After that, $10 \mu \mathrm{L}$ of the above suspensions were spread evenly on the LB agar and cultured overnight at $37^{\circ} \mathrm{C}$. The values of $\mathrm{OD}_{600}$ of the bacterial suspensions were measured using a microplate reader, and the antibacterial efficiency was calculated as follows:

$$
\text { Antibacterial efficiency }(\%)=\left(\mathrm{OD}_{\mathrm{P}}-\mathrm{OD}\right) /\left(\mathrm{OD}_{\mathrm{P}}-\mathrm{OD}_{\mathrm{N}}\right) \times 100 \%
$$

in which $\mathrm{OD}$ and $\mathrm{OD}_{\mathrm{P}}$ represent the absorbance of bacterial suspensions at $600 \mathrm{~nm}$ exposed to PSS-SQDs $\left(0.5-2.4 \mathrm{mg} / \mathrm{mL}\right.$ ) and LB broth (positive control), respectively. $\mathrm{OD}_{\mathrm{N}}$ is the absorbance of bacterial suspension at $600 \mathrm{~nm}$ in the absence of LB broth (negative control).

Verification of bacterial membrane damage. Propidium iodide (PI) was used to test the change of membrane permeability before and after the interactions of MRSA and PAE with PSS-SQDs, respectively. Suspensions of MRSA and PAE $\left(10^{6} \mathrm{CFU} / \mathrm{mL}\right)$ were treated with PBS buffer (control group) and $1.8 \mathrm{mg} / \mathrm{mL}$ of PSS-SQDs at $37^{\circ} \mathrm{C}$ for $1 \mathrm{~h}$ and $2 \mathrm{~h}$, respectively. Then, $50 \mu \mathrm{M}$ of PI was added and fluorescence intensity were recorded with excitation and emission wavelengths of $535 \mathrm{~nm}$ and $615 \mathrm{~nm}$, respectively. 3,3'-dipropylthiadicarbocyanine iodide $\left[\operatorname{diSC}_{3}(5)\right]$ was used to test the change of membrane potential before and after the interactions of MRSA and PAE with PSS-SQDs, respectively. In detail, $4 \mu \mathrm{M}$ of $\operatorname{diSC}_{3}(5)$ and $100 \mathrm{mM}$ of $\mathrm{KCl}$ were added into $10^{6} \mathrm{CFU} / \mathrm{mL}$ bacterial suspension and incubated for $1 \mathrm{~h}$ at $37^{\circ} \mathrm{C}$. Then, PBS buffer (control group) and $1.8 \mathrm{mg} / \mathrm{mL}$ of PSS-SQDs were added to the above suspension. The fluorescence intensity at $1 \mathrm{~h}$ and $2 \mathrm{~h}$ were recorded with excitation and emission wavelengths of $620 \mathrm{~nm}$ and $670 \mathrm{~nm}$, respectively.

The level of bacterial ATP detection. MRSA and PAE with $10^{6} \mathrm{CFU} / \mathrm{mL}$ were treated with PBS buffer, PSS, PSS-SNPs, and PSS-SQDs for 20 min, respectively. The final concentration of the regents was $1.8 \mathrm{mg} / \mathrm{mL}$. Then, the bacteria were collected by centrifugation at 8000 rpm for $3 \mathrm{~min}$. Next, the bacteria were cracked, and the supernatant was collected by 
centrifugation (12000 g, $\left.4{ }^{\circ} \mathrm{C}, 5 \mathrm{~min}\right)$. Finally, ATP Assay Kit was used for the detection of ATP levels in bacteria.

Live/dead bacterial staining assay. MRSA and PAE $\left(10^{8} \mathrm{CFU} / \mathrm{mL}\right)$ were centrifuged at $8000 \mathrm{rpm}$ for $3 \mathrm{~min}$ and washed three times with PBS buffer $(0.01 \mathrm{M}, \mathrm{pH} 7.4)$. Then, the bacterial suspension was mixed with $1.8 \mathrm{mg} / \mathrm{mL}$ of PSS-SQDs and PBS buffer (control group) for $20 \mathrm{~min}$, respectively. $10 \mathrm{mg}$ of acridine orange (AO) and $10 \mathrm{mg}$ of ethidium bromide (EB) were added into $10 \mathrm{~mL}$ PBS to obtain AO/EB fluorescent dye solution. The bacterial suspensions were stained with $\mathrm{AO} / \mathrm{EB}$ solution and incubated in dark for $15 \mathrm{~min}$. Excess dyes were removed by washing three times with PBS buffer. Fluorescence imaging of bacteria was conducted using a confocal laser scanning microscope.

Observation of bacterial morphology destruction. MRSA and PAE with $10^{8} \mathrm{CFU} / \mathrm{mL}$ were treated with PBS buffer (control group) and $1.8 \mathrm{mg} / \mathrm{mL}$ of PSS-SQDs for $20 \mathrm{~min}$, respectively. The bacterial suspension was centrifugated at $8000 \mathrm{rpm}$ for $3 \mathrm{~min}$, and then washed three times with PBS buffer. The collected bacteria were fixed with $2.5 \%$ glutaraldehyde and kept at $4{ }^{\circ} \mathrm{C}$ overnight. Finally, the bacteria were dehydrated with different concentrations $(30 \%, 50 \%, 70 \%, 90 \%$, and $100 \%)$ of ethanol and their morphology was characterized by scanning electron microscope (SEM) and transmission electron microscope (TEM).

In vitro biofilm dispersion assay. Firstly, $200 \mu \mathrm{L}$ of MRSA and PAE $\left(10^{8} \mathrm{CFU} / \mathrm{mL}\right)$ were added to the 96 -well plates and incubated at $37^{\circ} \mathrm{C}$ for $24 \mathrm{~h}$ to form biofilm. After that, the bacteria suspension was removed from each well. Then, PBS buffer, PSS, PSS-SNPs, and PSS-SQDs with final concentration of $1.8 \mathrm{mg} / \mathrm{mL}$ were added into different wells, respectively. After incubation for $3 \mathrm{~h}$, the biofilm was fixed with methanol for $30 \mathrm{~min}$. Then, $0.1 \%$ crystal violet was added to each well and incubated in dark to stain the biofilm. After another $30 \mathrm{~min}$, the wells were syringed with PBS buffer to remove unbound crystal violet. Finally, 95\% ethanol was added to dissolve the dye and the absorbance at $590 \mathrm{~nm}$ of each 
well was recorded with a microplate reader to evaluate the biofilm biomass.

Reactive oxygen species (ROS) detection. First, ABDA was used as a ROS indicator to verify the generation of ROS in solution. In detail, $50 \mathrm{mM}$ of ABDA solution in DMSO was mixed with $1.8 \mathrm{mg} / \mathrm{mL}$ PSS-SQDs and $10^{8} \mathrm{CFU} / \mathrm{mL}$ bacteria (MRSA or PAE) for different time. The generation of ROS could be verified by monitoring the absorbance decrease of ABDA at $378 \mathrm{~nm}$ along with the increase of time. Similarly, PSS-SNPs with the same concentration were also studied as a comparison.

Then, electron paramagnetic resonance (ERP) was also employed to measure the generated different types of ROS. In detail, PSS-SQDs were added into the bacteria with logarithmic phase and mixed together. The EPR signal of the samples at $1 \mathrm{~min}, 5 \mathrm{~min}$, and 10 $\min$ were recorded, using 5,5-dimethyl-1-pyrroline-N-oxide (DMPO) and 2,2,6,6-tetramethylpiperidine (TEMP) to capture $\bullet \mathrm{OH}$ and ${ }^{1} \mathrm{O}_{2}$, respectively.

\section{Evaluation of antibacterial activity in vivo.}

Based on the " $3 R$ " principle (Reduction/ Replacement/ Refinement), twenty-four healthy BALB/c mice (6-8 weeks, female) were randomly divided into two groups (twelve in each group), namely, MRSA-infected and PAE-infected groups. The above two groups were then each randomly assigned into four experimental groups (three mice in each group for parallel tests, $n=3$ ), wherein the mice were treated with PBS buffer, PSS, PSS-SNPs, and PSS-SQDs, respectively. Specifically, $100 \mu \mathrm{L}$ of MRSA and PAE suspension $\left(10^{8} \mathrm{CFU} / \mathrm{mL}\right)$ was subcutaneously inoculated into the back of the mice, respectively. After $24 \mathrm{~h}$, each group started to be treated with $50 \mu \mathrm{L}$ of PBS buffer (0.01 M, pH 7.4), PSS solution $(1.2 \mathrm{mg} / \mathrm{mL})$, PSS-SNPs $(1.2 \mathrm{mg} / \mathrm{mL})$, and PSS-SQDs $(1.2 \mathrm{mg} / \mathrm{mL})$, which were subcutaneously injected into the infected skin of the mice for treatment every day. The wound area and body weight of the mice in each group were recorded throughout the whole treatment period. When the treatment completed, the residual bacteria were collected from the tissue fluid at wounds, coated on LB agar plates, and incubated for $24 \mathrm{~h}$ at $37{ }^{\circ} \mathrm{C}$. In order to assess the in vivo therapeutic effect by different treatments, the infected skin tissues were excised when the 
treatment completed, which were fixed in $4 \%$ paraformaldehyde, embedded into paraffin, cut in sections, and stained with hematoxylin and eosin (H\&E) and Masson for histological investigations.

Hemolysis test. Hemolysis was investigated to evaluate the blood compatibility of the PSS-SQDs and PSS-SNPs. Firstly, anticoagulant venous blood was centrifuged (8000 rpm, 5 min) and washed with $0.9 \% \mathrm{NaCl}$ solution for 3 times, and red blood cell (RBC) suspension in $0.9 \% \mathrm{NaCl}$ was obtained. Then, $50 \mu \mathrm{L}$ of $\mathrm{RBC}$ suspension was treated with different concentrations $(0.3,0.7,1.2,1.8,2.4,4.8$, and $7.2 \mathrm{mg} / \mathrm{mL})$ of PSS-SQDs and PSS-SNPs, respectively. $0.9 \% \mathrm{NaCl}$ solution and ultra-pure water was used as negative and positive control, respectively. After incubation for $1 \mathrm{~h}$ at $37^{\circ} \mathrm{C}$, the mixture was centrifuged at 6000 rpm for $5 \mathrm{~min}$. The absorbance of supernatant at $540 \mathrm{~nm}$ was measured. The hemolysis rate was calculated as follows: ${ }^{3}$

Hemolysis rate $(\%)=\left(A-A_{\mathrm{N}}\right) /\left(A_{\mathrm{P}}-A_{\mathrm{N}}\right) \times 100 \%$

in which $A, A_{\mathrm{N}}$ and $A_{\mathrm{P}}$ represent the absorbance of RBC exposed to PSS-SQDs/PSS-SNPs, $0.9 \% \mathrm{NaCl}$ solution (negative control), and ultra-pure water (positive control), respectively.

Cytotoxicity test. Human umbilical vein endothelial cells (HUVECs) were seeded into a 96-well plate at a density of $5 \times 10^{3}$ cells/well and incubated in $100 \mu \mathrm{L}$ of DMEM in a humidified incubator for $24 \mathrm{~h}$ (with $5 \% \mathrm{CO}_{2}$ at $37^{\circ} \mathrm{C}$ ). PSS-SQDs and PSS-SNPs with different concentrations $(0.3,0.7,1.2,1.8$, and $2.4 \mathrm{mg} / \mathrm{mL})$ were added to the cells, respectively. After incubation for $24 \mathrm{~h}, 20 \mu \mathrm{L}$ of MTS was added to each well of the plate, and the plate was incubated for another $2 \mathrm{~h}$. The absorbance of each well at $490 \mathrm{~nm}$ was measured with a microplate reader and the cell viability was calculated.

Toxicity evaluation of PSS-SQDs in vivo. To verify the biosafety of PSS-SQDs in vivo, the major organs of BALB/c mice including heart, liver, spleen, lung, and kidney were collected from MRSA-infected mice that had been treated by PBS (control group) and PSS-SQDs for 12 days, respectively. For each group, 3 mice were investigated in the treatment procedure, 
wherein one of them was randomly selected and sacrificed for histological observation. The organ tissues were fixed in $4 \%$ paraformaldehyde solution for $48 \mathrm{~h}$, embedded in paraffin, sectioned, stained with H\&E and Masson, and then observed by an optical microscope.

Statistical analysis. Each experiment was performed at least 3 times, and all quantitative data were presented as mean result \pm standard deviation (SD). Statistical analyses were conducted using Student's $t$-test by SPSS software. Values of $* p<0.05, * * p<0.01$ and $* * * p$ $<0.001$ were considered statistically significant.

\section{References:}

(1) Jiang, K.; Sun, S.; Zhang, L.; Lu, Y.; Wu, A.; Cai, C.; Lin, H. Red, Green, and Blue Luminescence by Carbon Dots: Full-Color Emission Tuning and Multicolor Cellular Imaging. Angew. Chem. Int. Ed. 2015, 54, 5360-5363.

(2) Lin, A.; Liu, Y.; Zhu, X.; Chen, X.; Liu, J.; Zhou, Y.; Qin, X.; Liu, J. Bacteria-Responsive Biomimetic Selenium Nanosystem for Multidrug-Resistant Bacterial Infection Detection and Inhibition. ACS Nano 2019, 13, 13965-13984.

(3) Yang, D.; Yang, G.; Yang, P.; Lv, R.; Gai, S.; Li, C.; He, F.; Lin, J. Assembly of Au Plasmonic Photothermal Agent and Iron Oxide Nanoparticles on Ultrathin Black Phosphorus for Targeted Photothermal and Photodynamic Cancer Therapy. Adv. Funct. Mater. 2017, 1700371. 


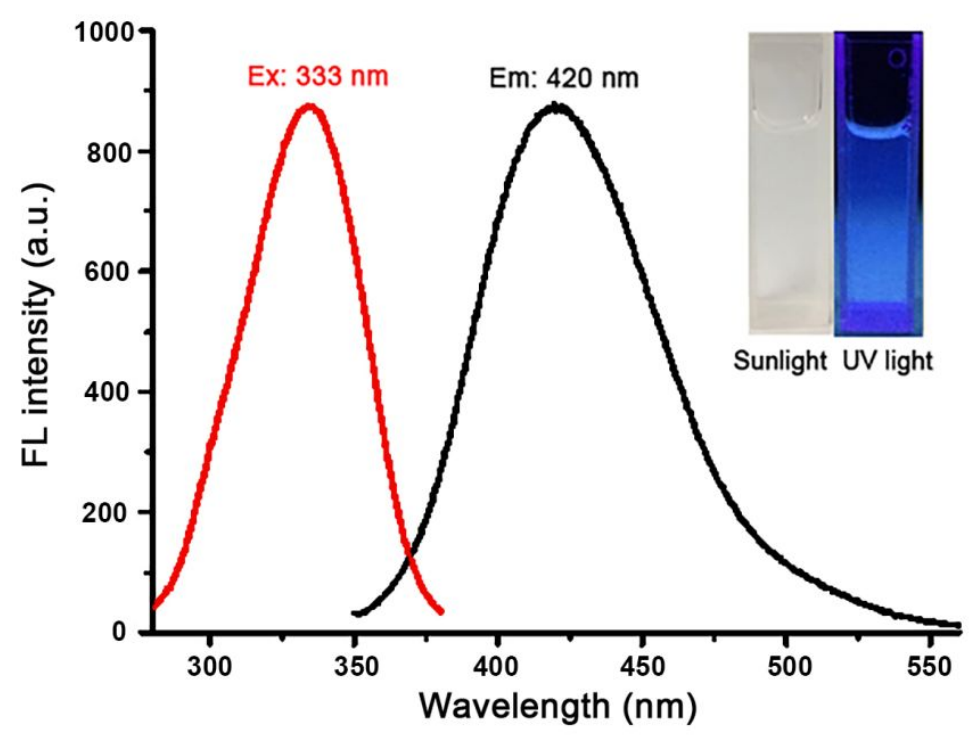

Figure S1. Maximum excitation (Ex: $333 \mathrm{~nm})$ and emission (Em: $420 \mathrm{~nm})$ spectra of the PSS-SQDs. Inset is the photograph of the corresponding solution under sunlight and $365 \mathrm{~nm}$ UV light. 


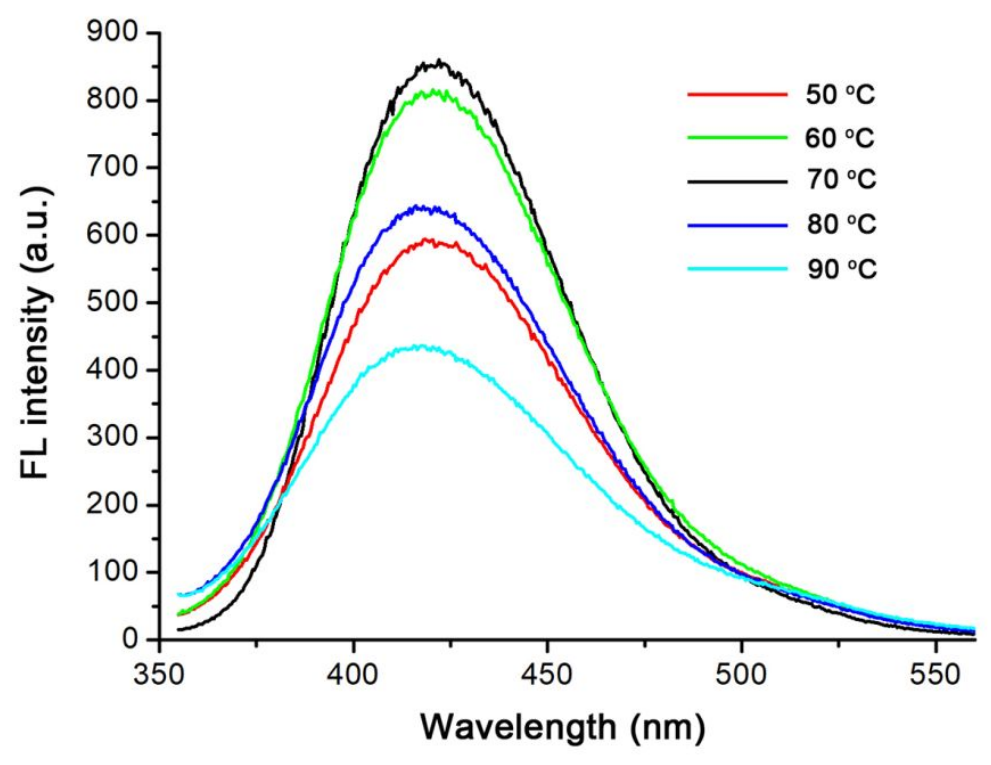

Figure S2. Fluorescence spectra of the PSS-SQDs synthesized at different temperatures. Other conditions: sulfur powder, $1.5 \mathrm{~g}$; PSS, $0.15 \mathrm{~g}$; NaOH, 4 g; reaction time, $12 \mathrm{~h} ; \mathrm{H}_{2} \mathrm{O}_{2}$, $4.8 \mathrm{wt} \%$. 

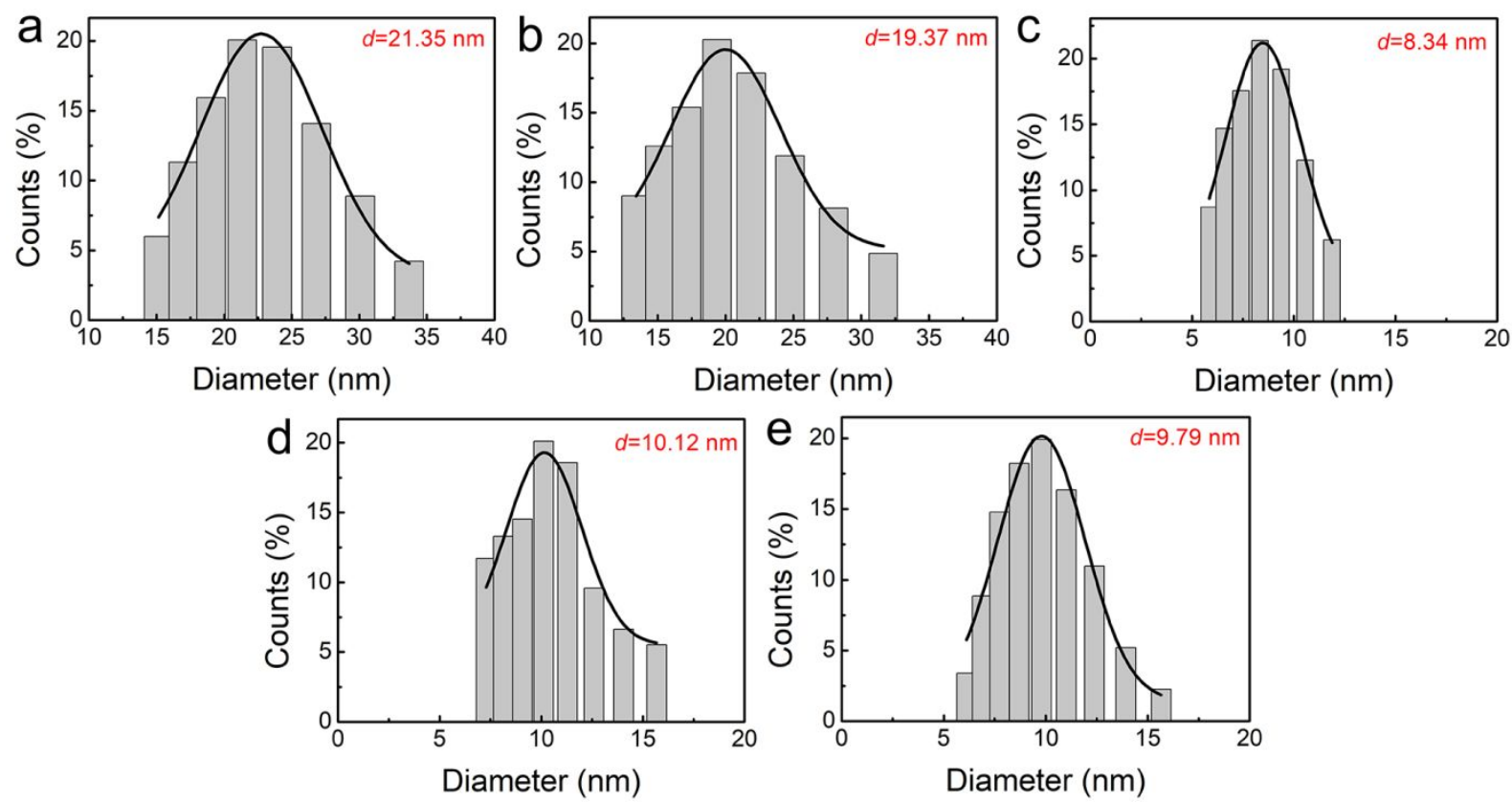

Figure S3. DLS results of the PSS-SQDs synthesized at different temperatures: (a) $50{ }^{\circ} \mathrm{C}$, (b) $60{ }^{\circ} \mathrm{C}$, (c) $70{ }^{\circ} \mathrm{C}$, (d) $80{ }^{\circ} \mathrm{C}$, and (e) $90{ }^{\circ} \mathrm{C}$. Other conditions: sulfur powder, $1.5 \mathrm{~g}$; PSS, $0.15 \mathrm{~g}$; $\mathrm{NaOH}, 4 \mathrm{~g}$; reaction time, $12 \mathrm{~h} ; \mathrm{H}_{2} \mathrm{O}_{2}, 4.8 \mathrm{wt} \%$. 


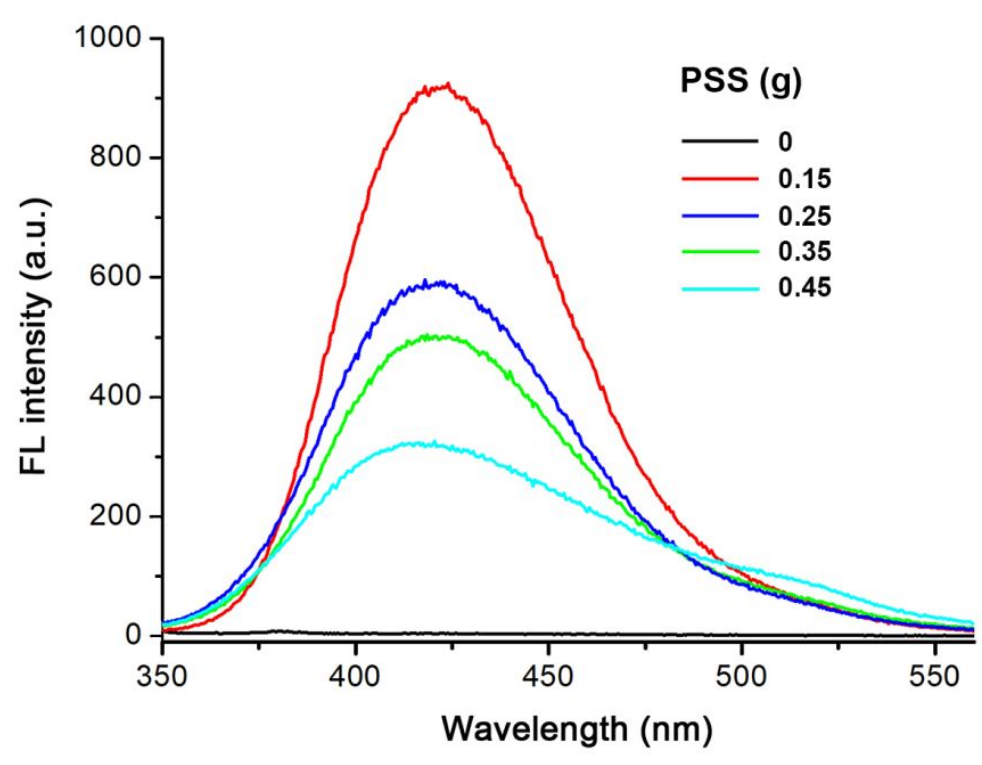

Figure S4. Fluorescence spectra of the PSS-SQDs synthesized with different amounts of PSS. Other conditions: sulfur powder, $1.5 \mathrm{~g}$; $\mathrm{NaOH}, 4 \mathrm{~g}$; temperature, $70{ }^{\circ} \mathrm{C}$; reaction time, $12 \mathrm{~h}$; $\mathrm{H}_{2} \mathrm{O}_{2}, 4.8$ wt $\%$. 

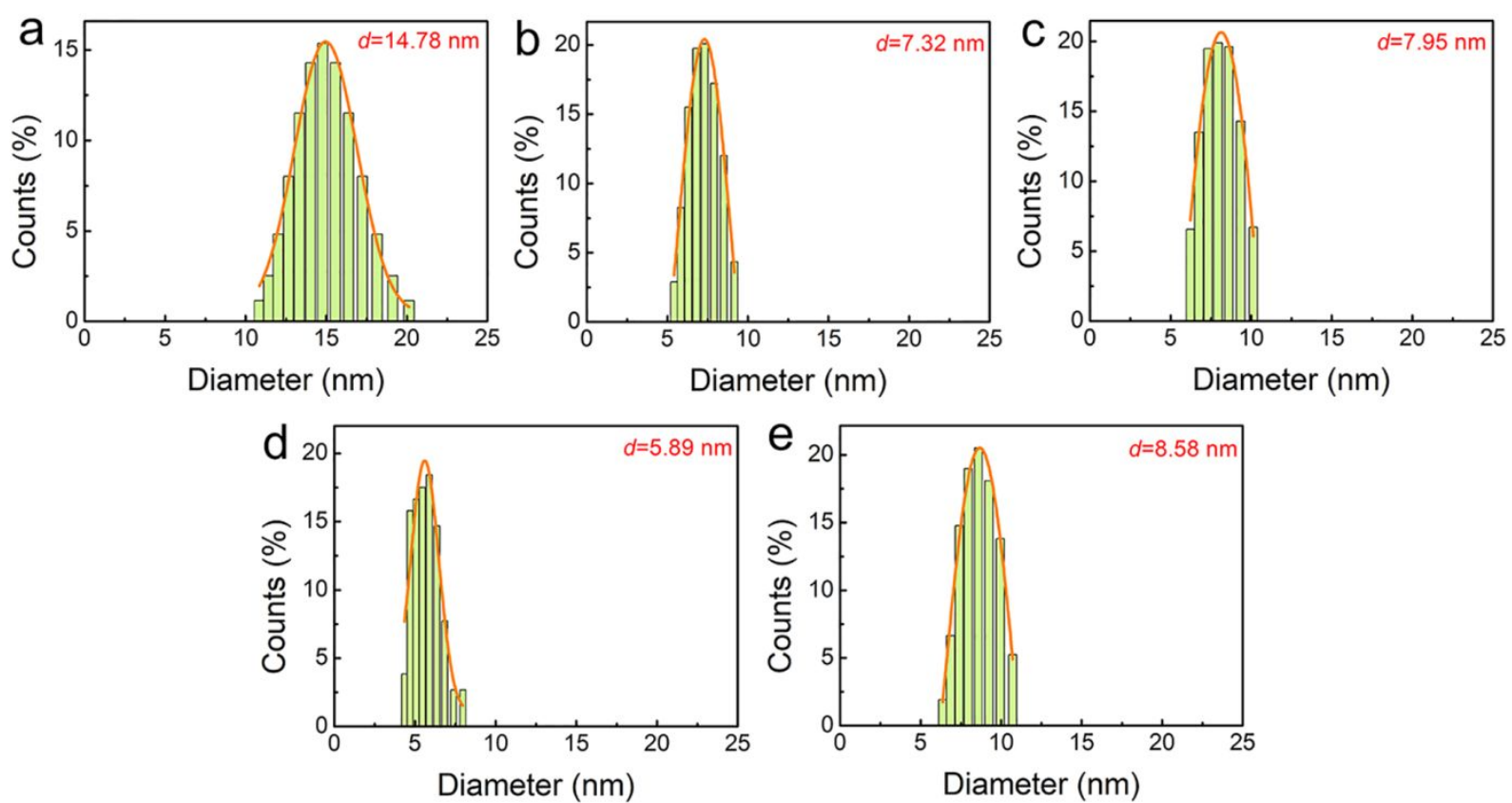

Figure S5. DLS results of the PSS-SQDs synthesized with different amounts of PSS: (a) $0 \mathrm{~g}$, (b) $0.15 \mathrm{~g}$, (c) $0.25 \mathrm{~g}$, (d) $0.35 \mathrm{~g}$, and (e) $0.45 \mathrm{~g}$. Other conditions: sulfur powder, $1.5 \mathrm{~g}$; $\mathrm{NaOH}, 4 \mathrm{~g}$; temperature, $70{ }^{\circ} \mathrm{C}$; reaction time, $12 \mathrm{~h} ; \mathrm{H}_{2} \mathrm{O}_{2}, 4.8 \mathrm{wt} \%$. 


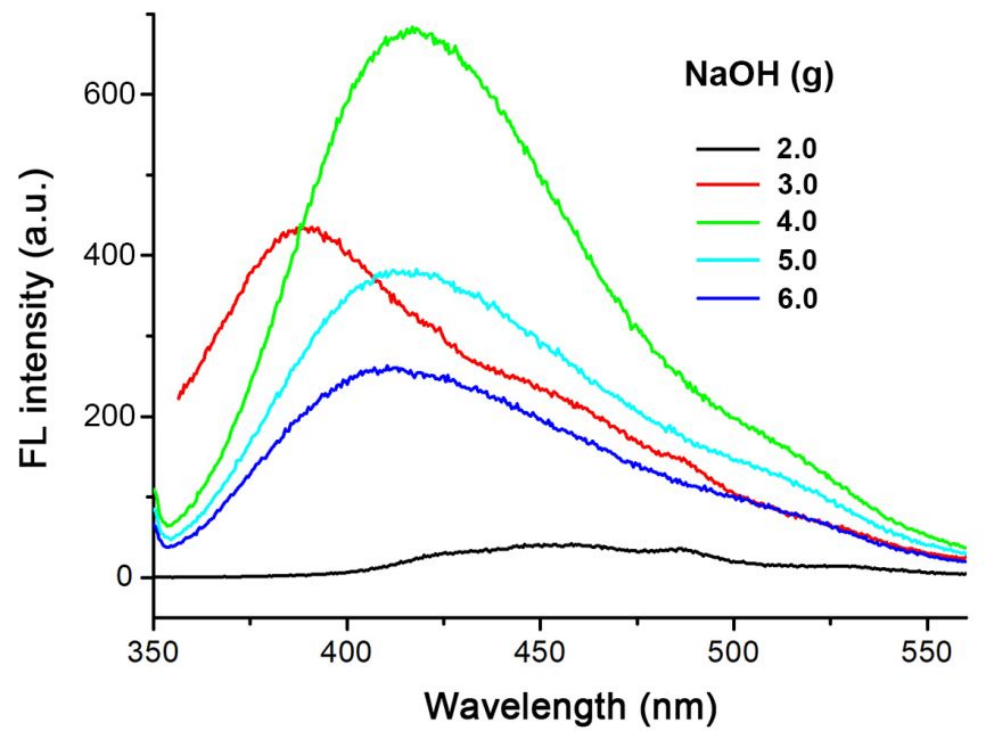

Figure S6. Fluorescence spectra of the PSS-SQDs synthesized with different amounts of $\mathrm{NaOH}$. Other conditions: sulfur powder, $1.5 \mathrm{~g}$; PSS, $0.15 \mathrm{~g}$; temperature, $70{ }^{\circ} \mathrm{C}$; reaction time, $12 \mathrm{~h} ; \mathrm{H}_{2} \mathrm{O}_{2}, 4.8 \mathrm{wt} \%$. 

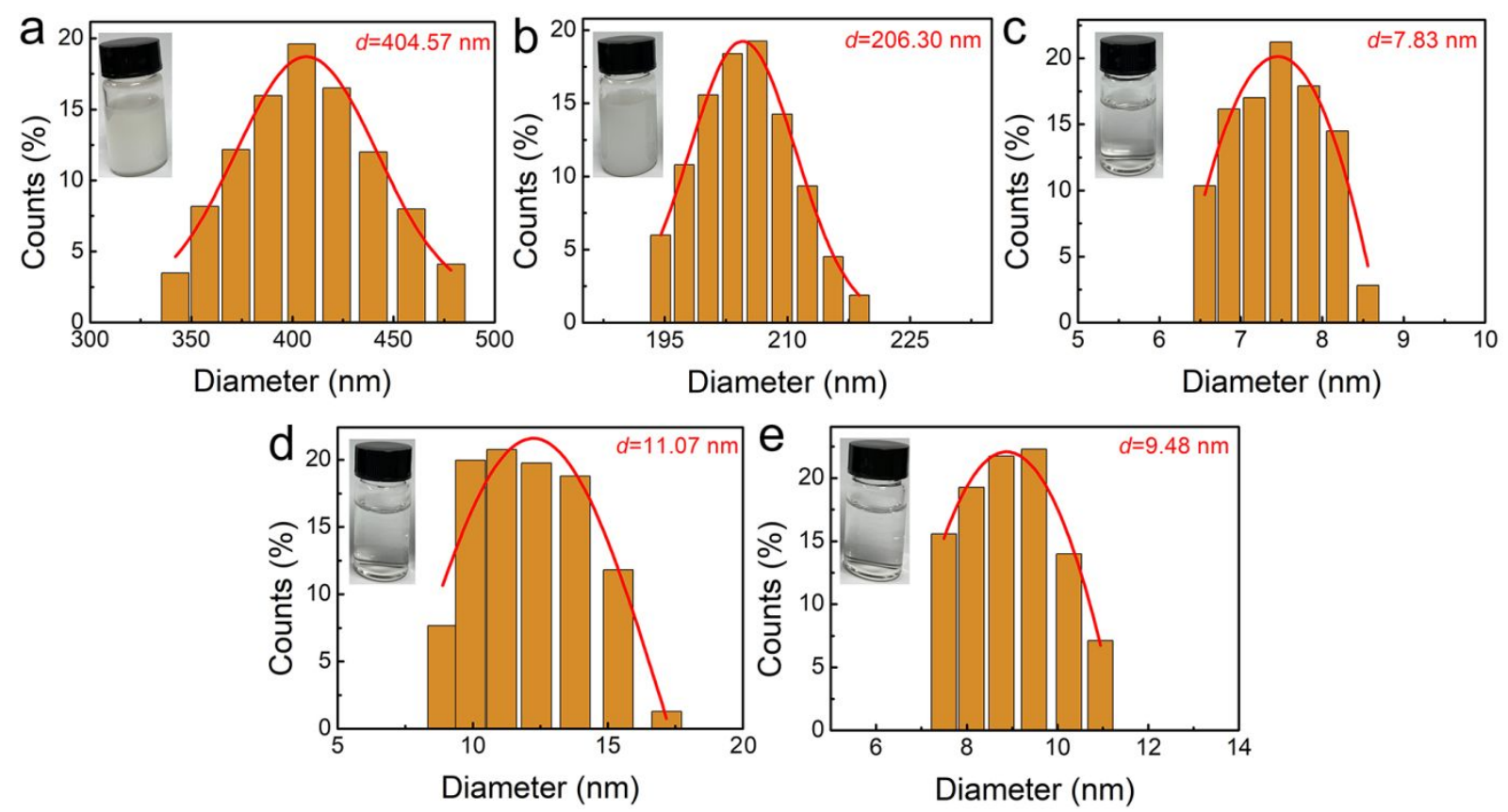

Figure S7. DLS results of the PSS-SQDs synthesized with different amounts of $\mathrm{NaOH}$ : (a) 2 g, (b) $3 \mathrm{~g}$, (c) $4 \mathrm{~g}$, (d) $5 \mathrm{~g}$, and (e) $6 \mathrm{~g}$. Inset is the corresponding picture of each sample. Other conditions: sulfur powder, $1.5 \mathrm{~g}$; PSS, $0.15 \mathrm{~g}$; temperature, $70{ }^{\circ} \mathrm{C}$; reaction time, $12 \mathrm{~h} ; \mathrm{H}_{2} \mathrm{O}_{2}$, $4.8 \mathrm{wt} \%$. 


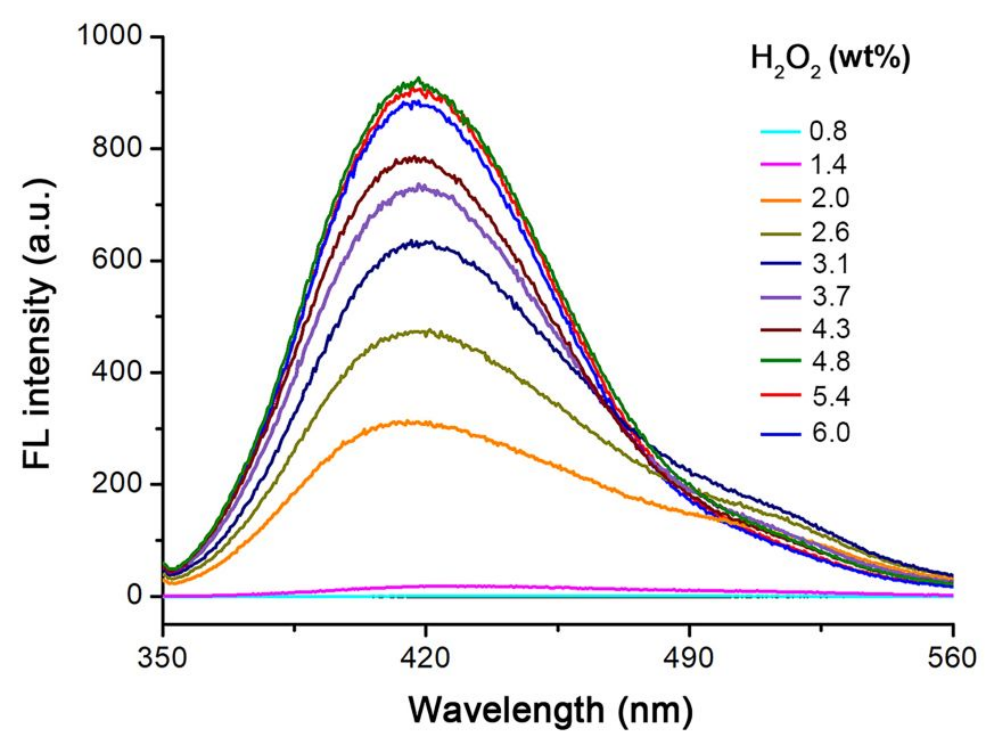

Figure S8. Fluorescence spectra of the PSS-SQDs synthesized in the presence of different amounts of $\mathrm{H}_{2} \mathrm{O}_{2}$. Other conditions: sulfur powder, $1.5 \mathrm{~g}$; PSS, $0.15 \mathrm{~g}$; $\mathrm{NaOH}, 4 \mathrm{~g}$; temperature, $70^{\circ} \mathrm{C}$; reaction time, $12 \mathrm{~h}$. 

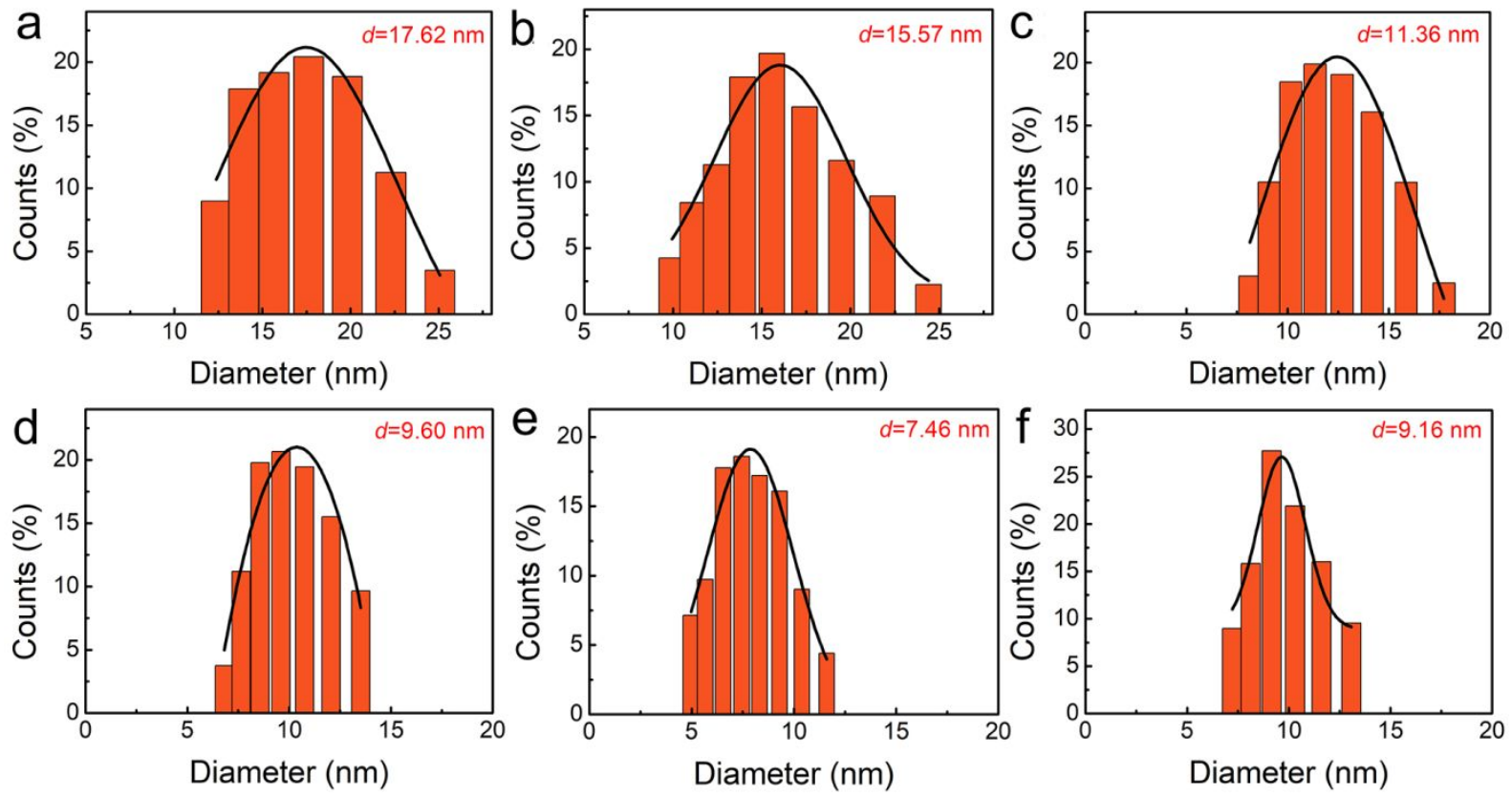

Figure S9. DLS results of the PSS-SQDs synthesized in the presence of different amounts of $\mathrm{H}_{2} \mathrm{O}_{2}$ : (a) 0 , (b) $0.8 \mathrm{wt} \%$, (c) $2.6 \mathrm{wt} \%$, (d) $3.7 \mathrm{wt} \%$, (e) $4.8 \mathrm{wt} \%$, and (f) $6.0 \mathrm{wt} \%$. Other conditions: sulfur powder, $1.5 \mathrm{~g}$; PSS, $0.15 \mathrm{~g}$; NaOH, $4 \mathrm{~g}$; temperature, $70{ }^{\circ} \mathrm{C}$; reaction time, $12 \mathrm{~h}$. 


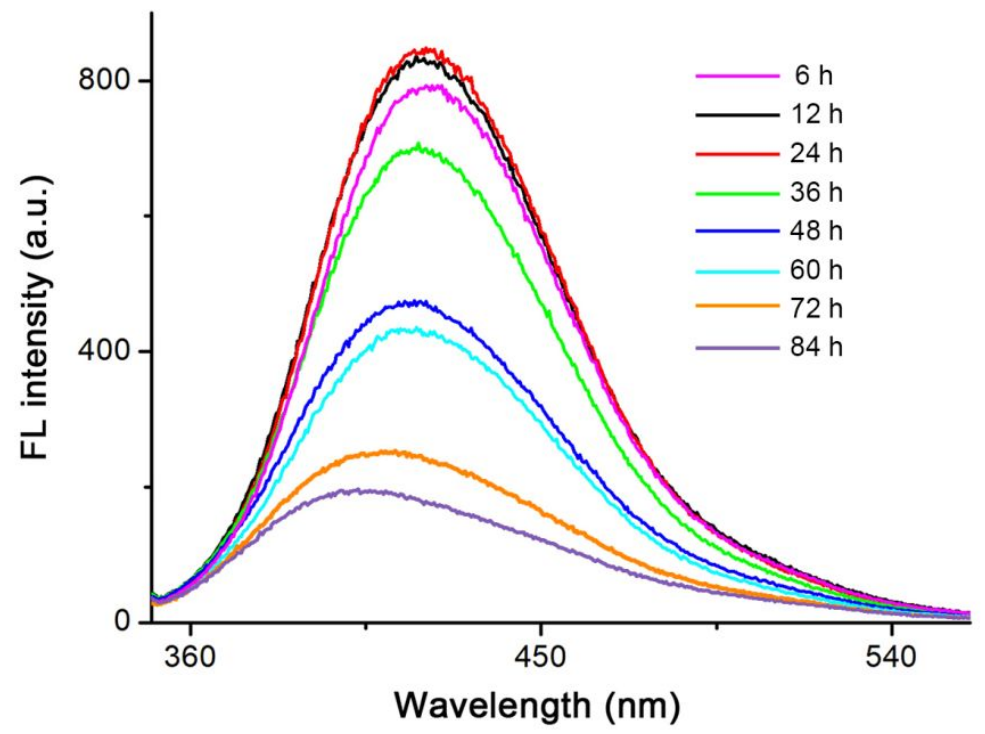

Figure S10. Fluorescence spectra of the PSS-SQDs synthesized at different reaction time using an oil bath. Other conditions: sulfur powder, $1.5 \mathrm{~g}$; PSS, $0.15 \mathrm{~g}$; NaOH, $4 \mathrm{~g}$; temperature, $70{ }^{\circ} \mathrm{C} ; \mathrm{H}_{2} \mathrm{O}_{2}, 4.8 \mathrm{wt} \%$. 

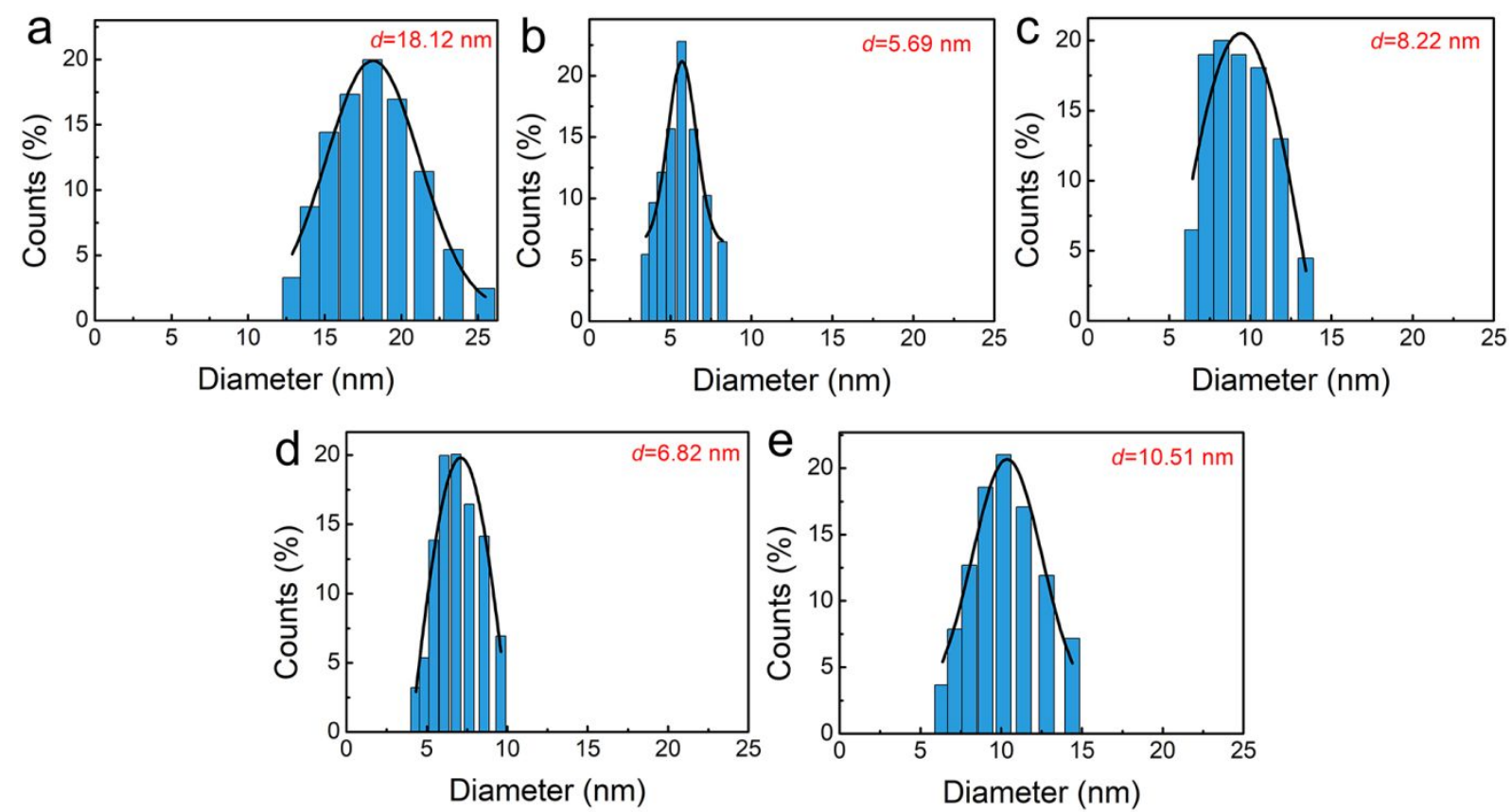

Figure S11. DLS results of the PSS-SQDs synthesized at different reaction time using an oil bath: a) $8 \mathrm{~h}$, b) $12 \mathrm{~h}$, c) $16 \mathrm{~h}$, d) $20 \mathrm{~h}$, and e) $24 \mathrm{~h}$. Other conditions: sulfur powder, $1.5 \mathrm{~g}$; PSS, $0.15 \mathrm{~g} ; \mathrm{NaOH}, 4 \mathrm{~g}$; temperature, $70{ }^{\circ} \mathrm{C} ; \mathrm{H}_{2} \mathrm{O}_{2}, 4.8 \mathrm{wt} \%$. 


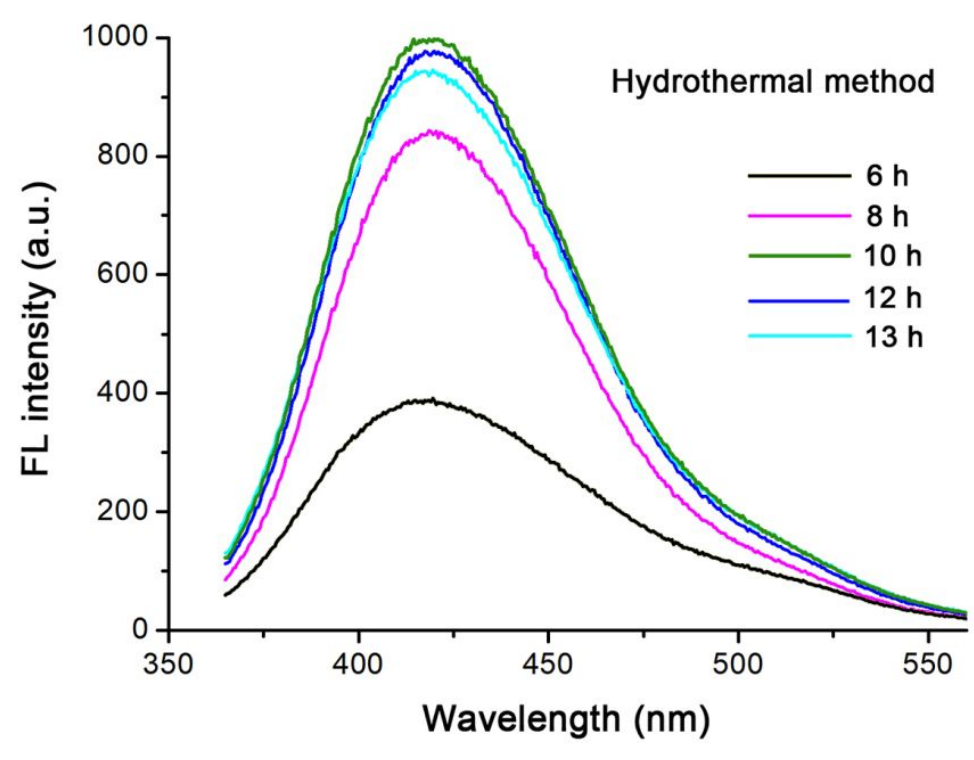

Figure S12. Fluorescence spectra of the PSS-SQDs synthesized at different reaction time by hydrothermal method. Other conditions: sulfur powder, $1.5 \mathrm{~g}$; PSS, $0.15 \mathrm{~g}$; NaOH, $4 \mathrm{~g}$; temperature, $70{ }^{\circ} \mathrm{C} ; \mathrm{H}_{2} \mathrm{O}_{2}, 4.8 \mathrm{wt} \%$. 


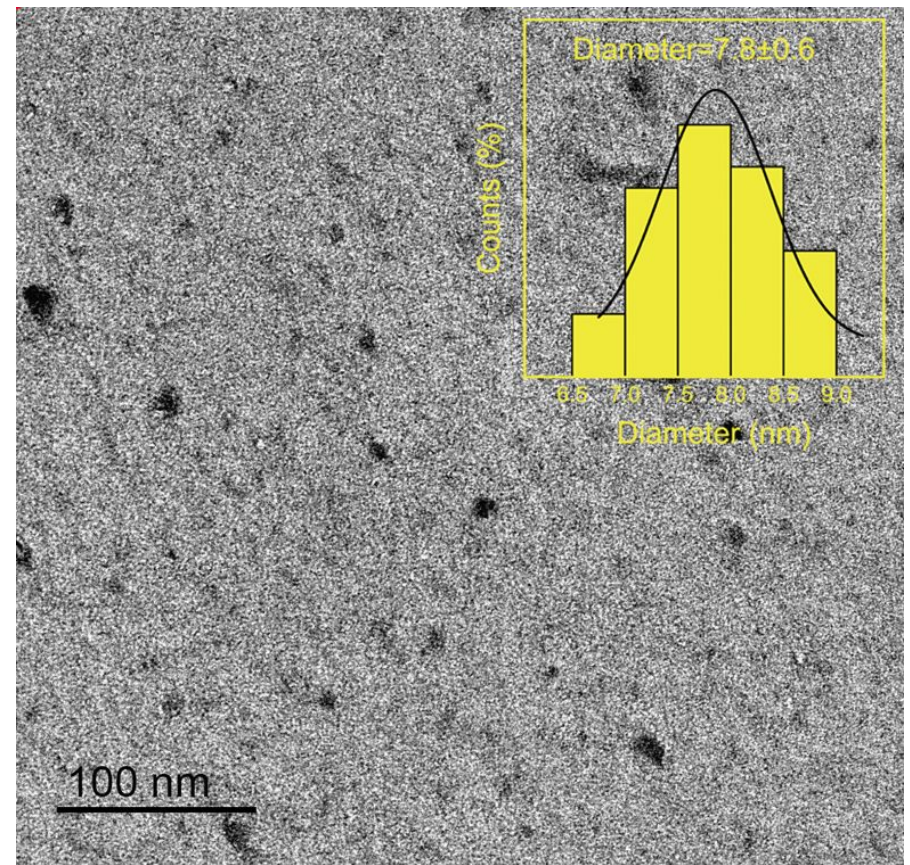

Figure S13. Transmission electron microscopy (TEM) image and size distribution (inset) of PSS-stabilized sulfur nanoparticles (PSS-SNPs). 


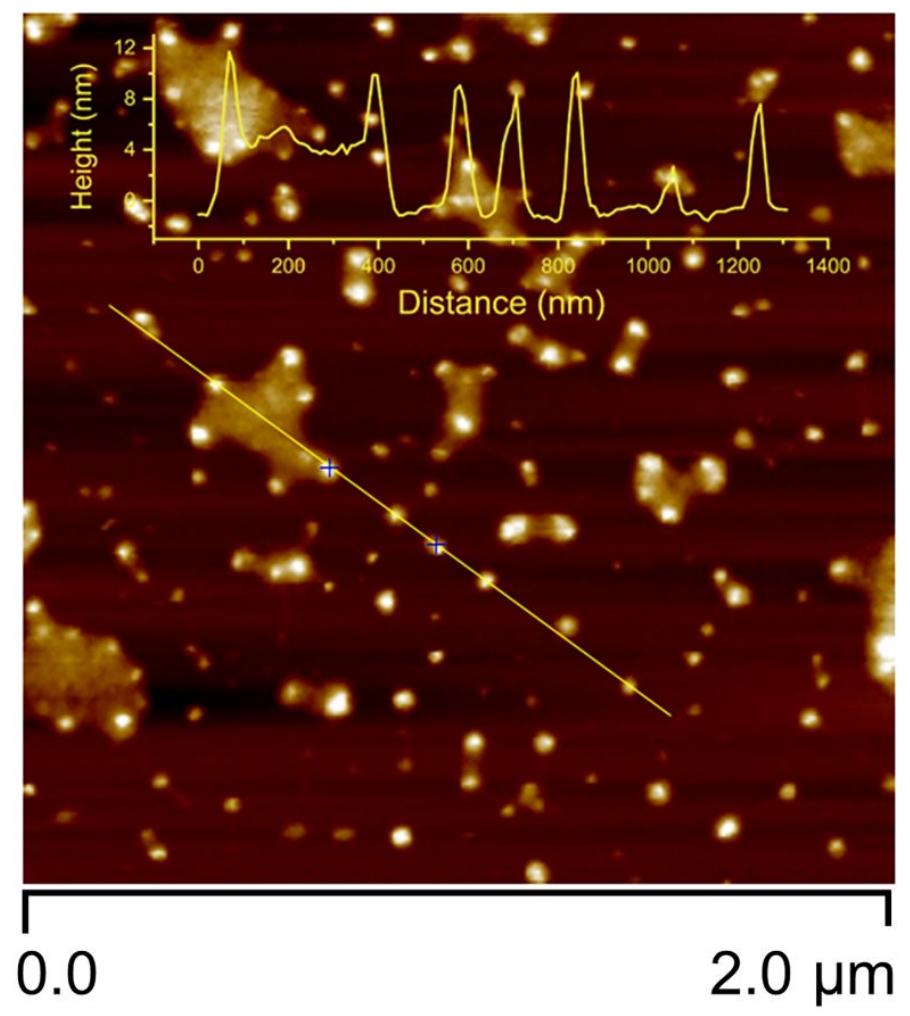

Figure S14. Atomic force microscopy (AFM) image and height measurements of PSS-stabilized sulfur nanoparticles (PSS-SNPs). 


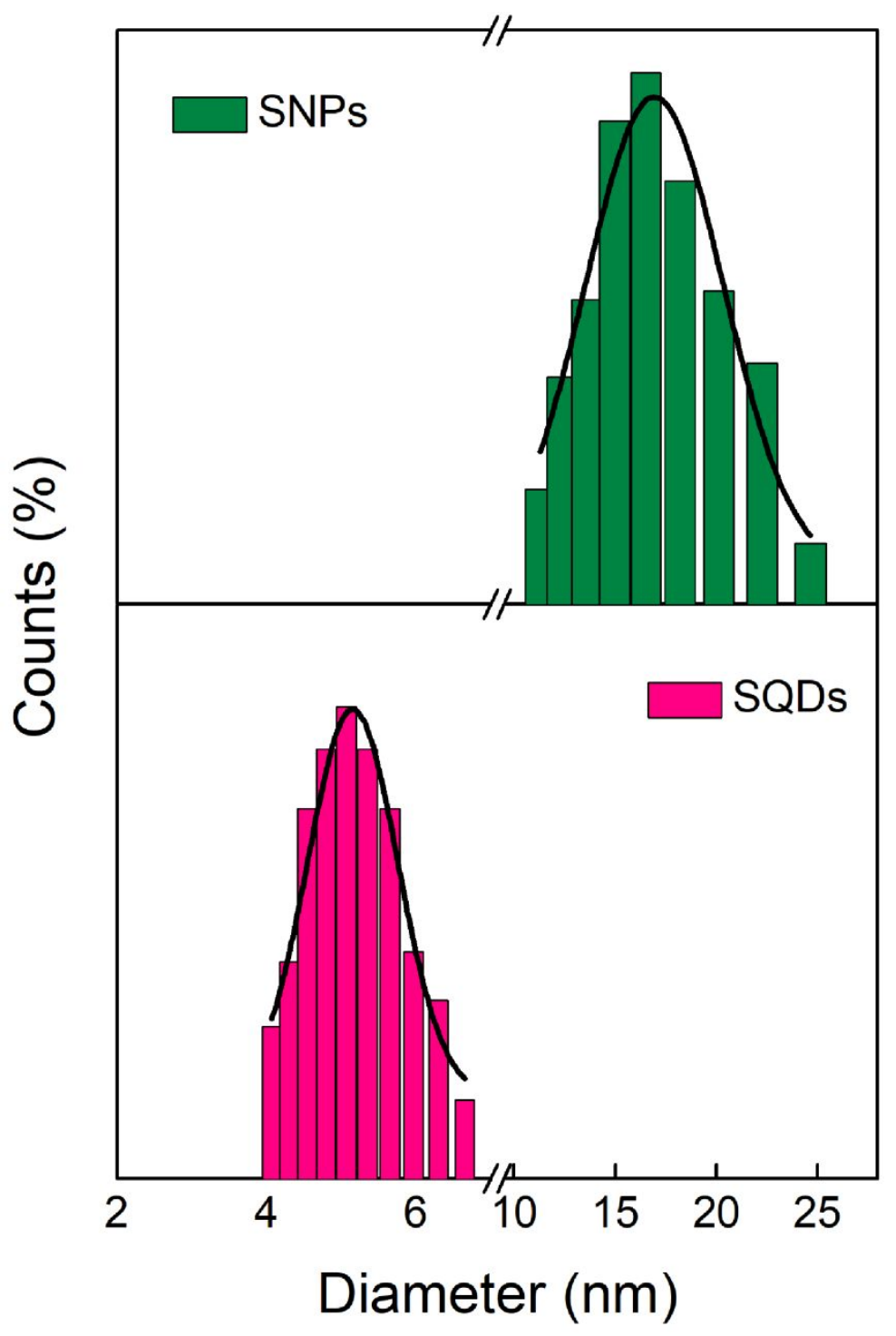

Figure S15. Dynamic light scattering (DLS) results of typical PSS-SNPs (top) and PSS-SQDs (down), with average hydrodynamic diameters of $15.6 \mathrm{~nm}$ and $5.1 \mathrm{~nm}$, respectively. 


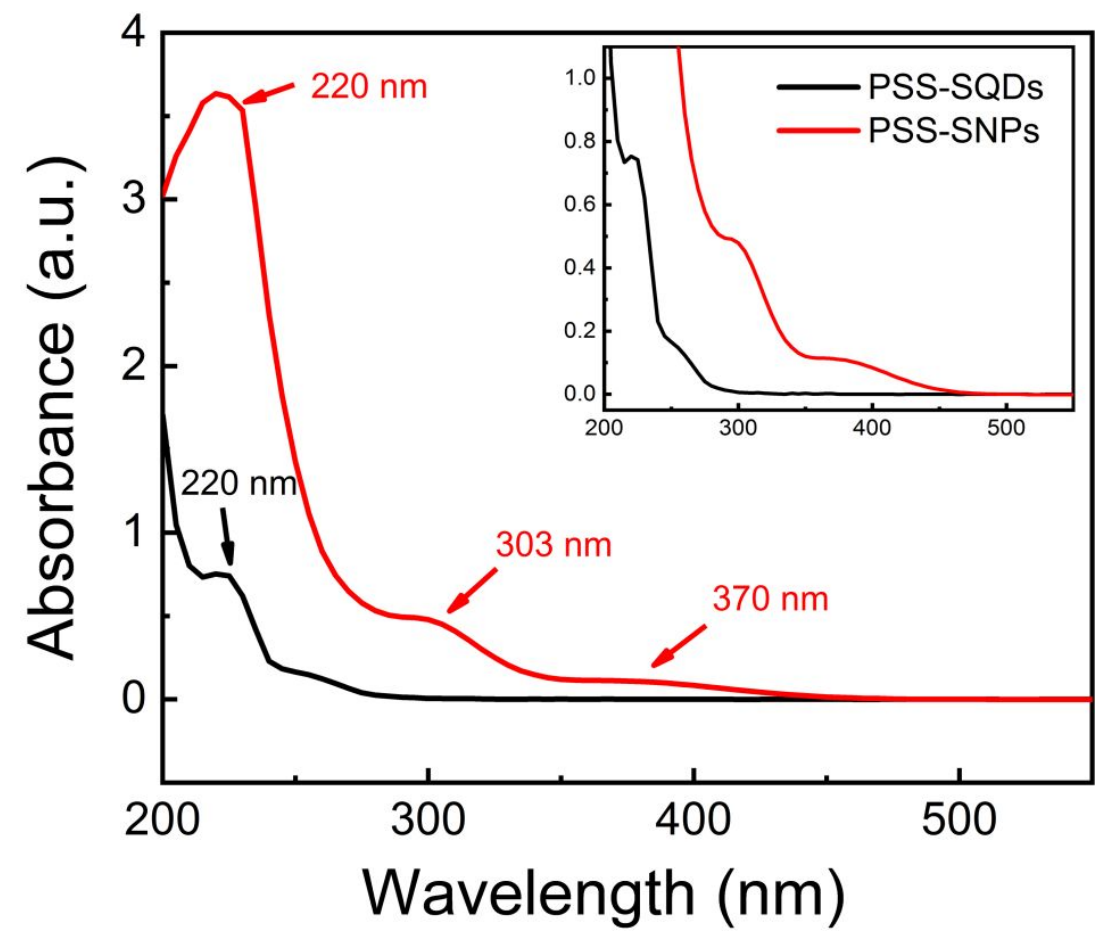

Figure S16. UV-vis absorption spectra of PSS-SNPs (red line) and PSS-SQDs (black line). 


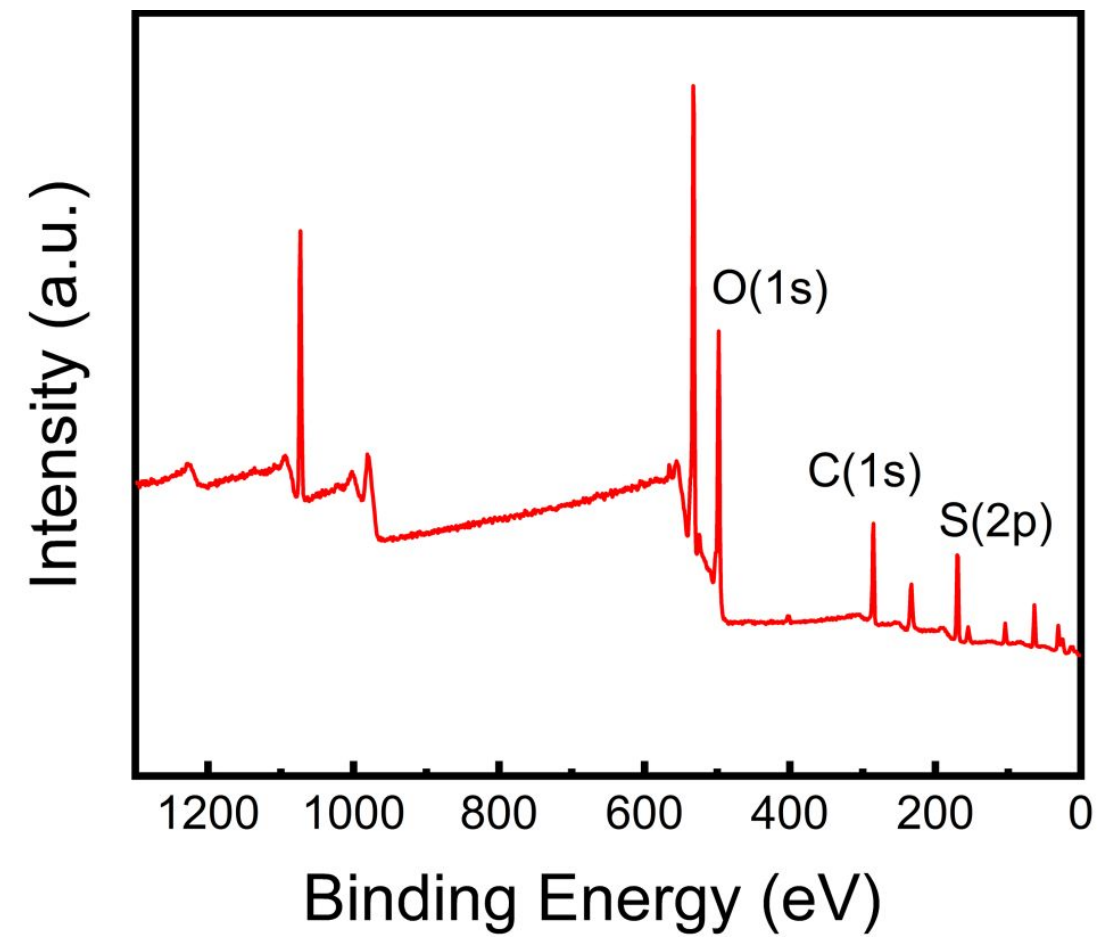

Figure S17. X-ray photoelectron spectroscopy (XPS) spectrum of the as-prepared PSS-SQDs. 


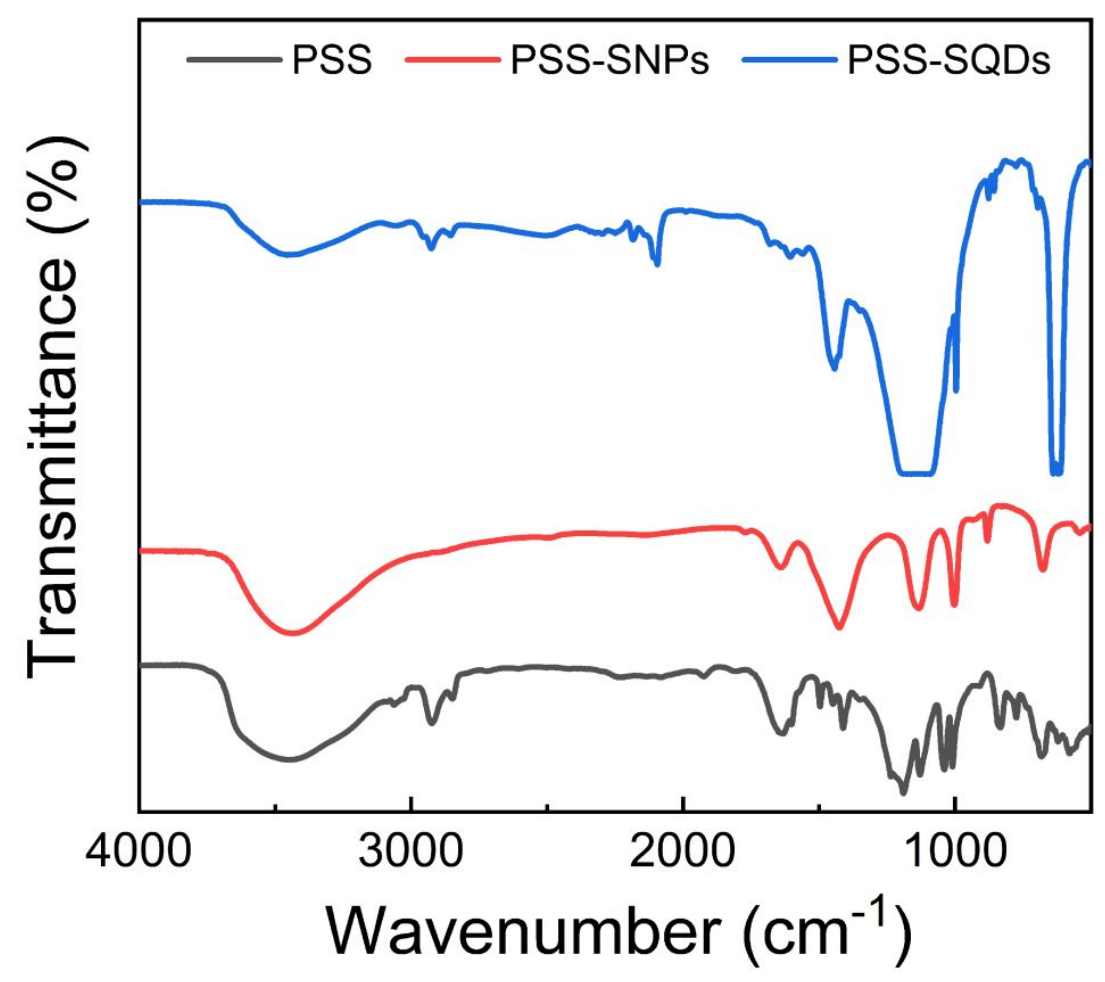

Figure S18. Fourier Transform infrared (FTIR) spectra of PSS, PSS-SNPs and PSS-SQDs. 


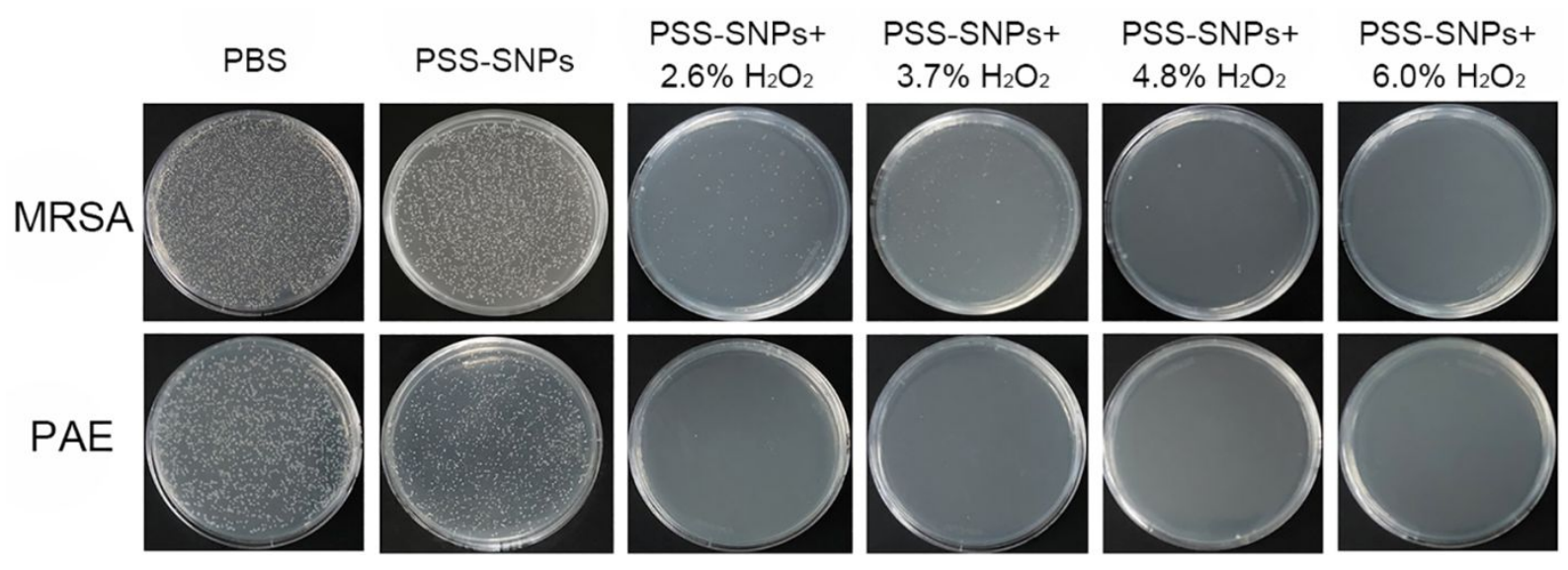

Figure S19. Antibacterial performances of PSS-SNPs and PSS-SQDs toward MRSA and PAE on LB agar, respectively. The PSS-SQDs with different sizes and surface states were obtained by reacting PSS-SNPs with different concentrations of $\mathrm{H}_{2} \mathrm{O}_{2}$. 

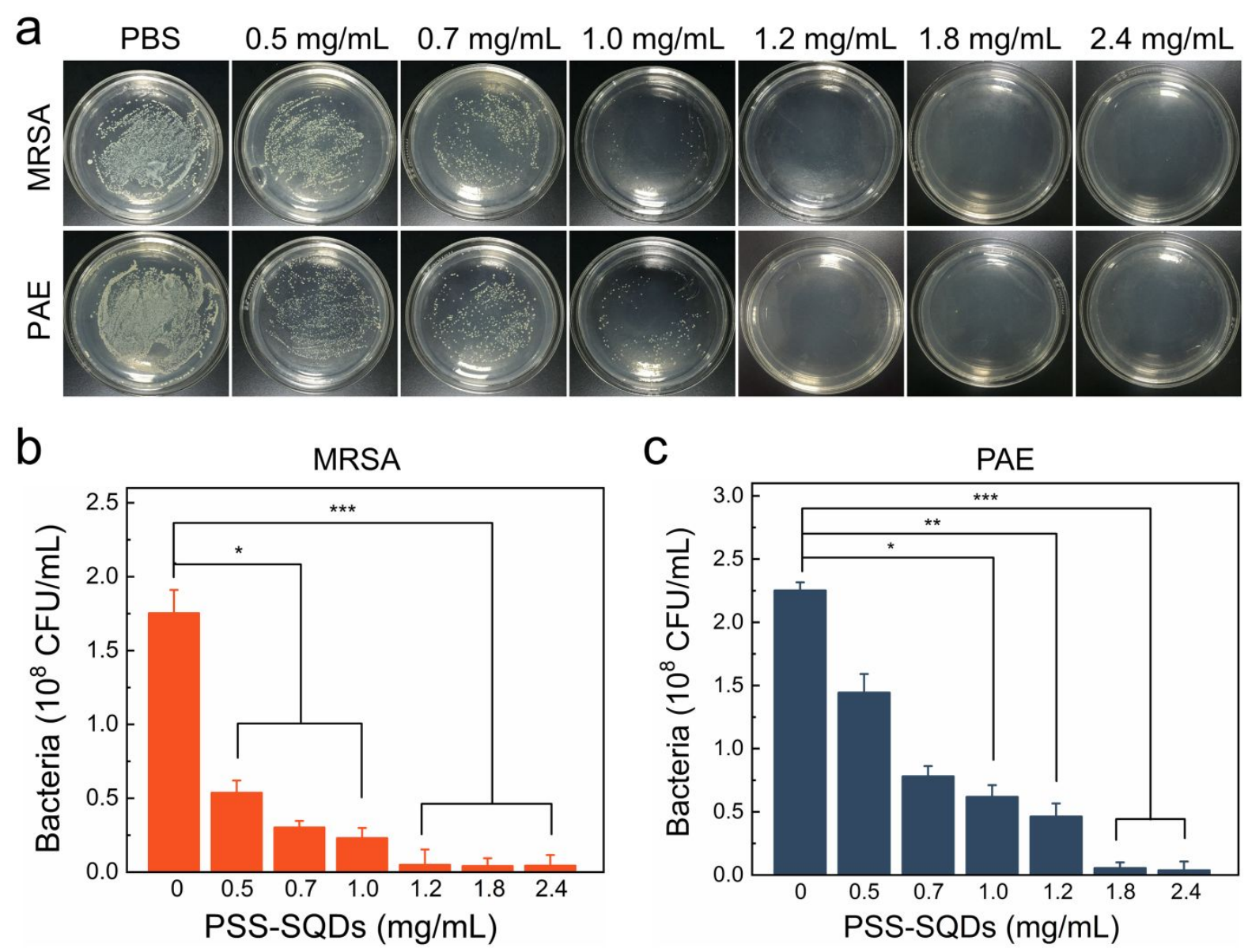

Figure S20. The minimum inhibitory concentration (MIC) of PSS-SQDs. (a) Growth of MRSA and PAE on LB agar in the presence of different concentrations of PSS-SQDs, respectively. Growth of (b) MRSA and (c) PAE in LB broth in the presence of different concentrations of PSS-SQDs, where statistical analysis was also carried. Error bars represent the standard deviation of three parallel tests. Asterisks indicate significant differences $\left({ }^{*} p<\right.$ $0.05, * * p<0.01, * * * p<0.001)$. 


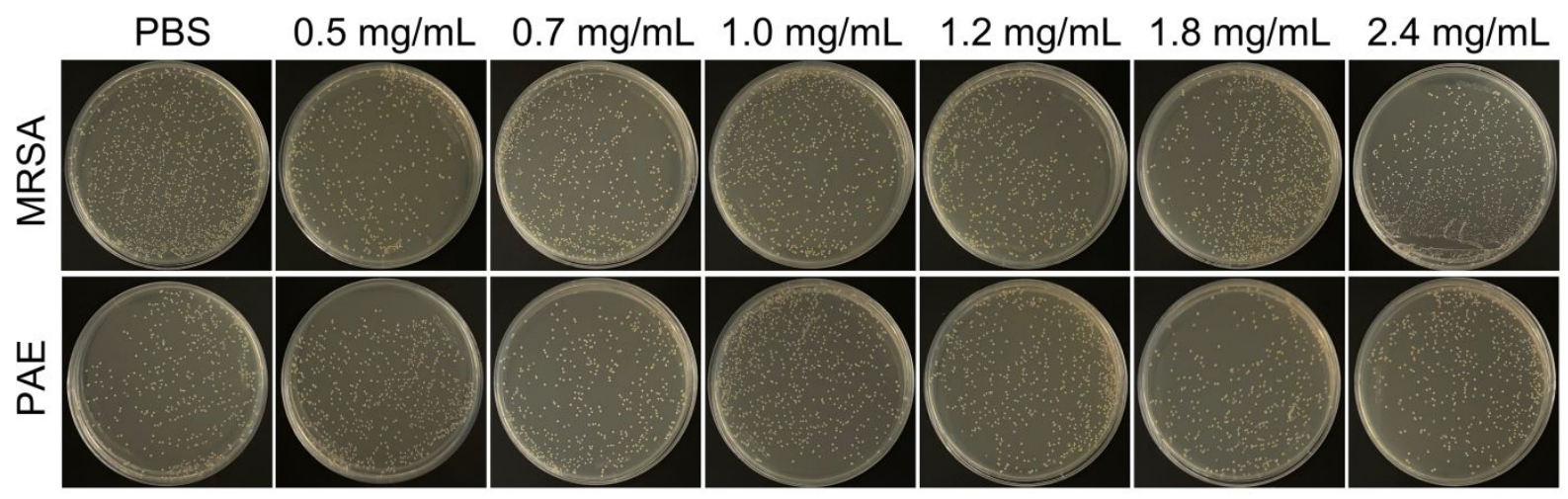

Figure S21. Antibacterial performance of PSS-SNPs with different concentrations toward MRSA and PAE on LB agar, respectively. 


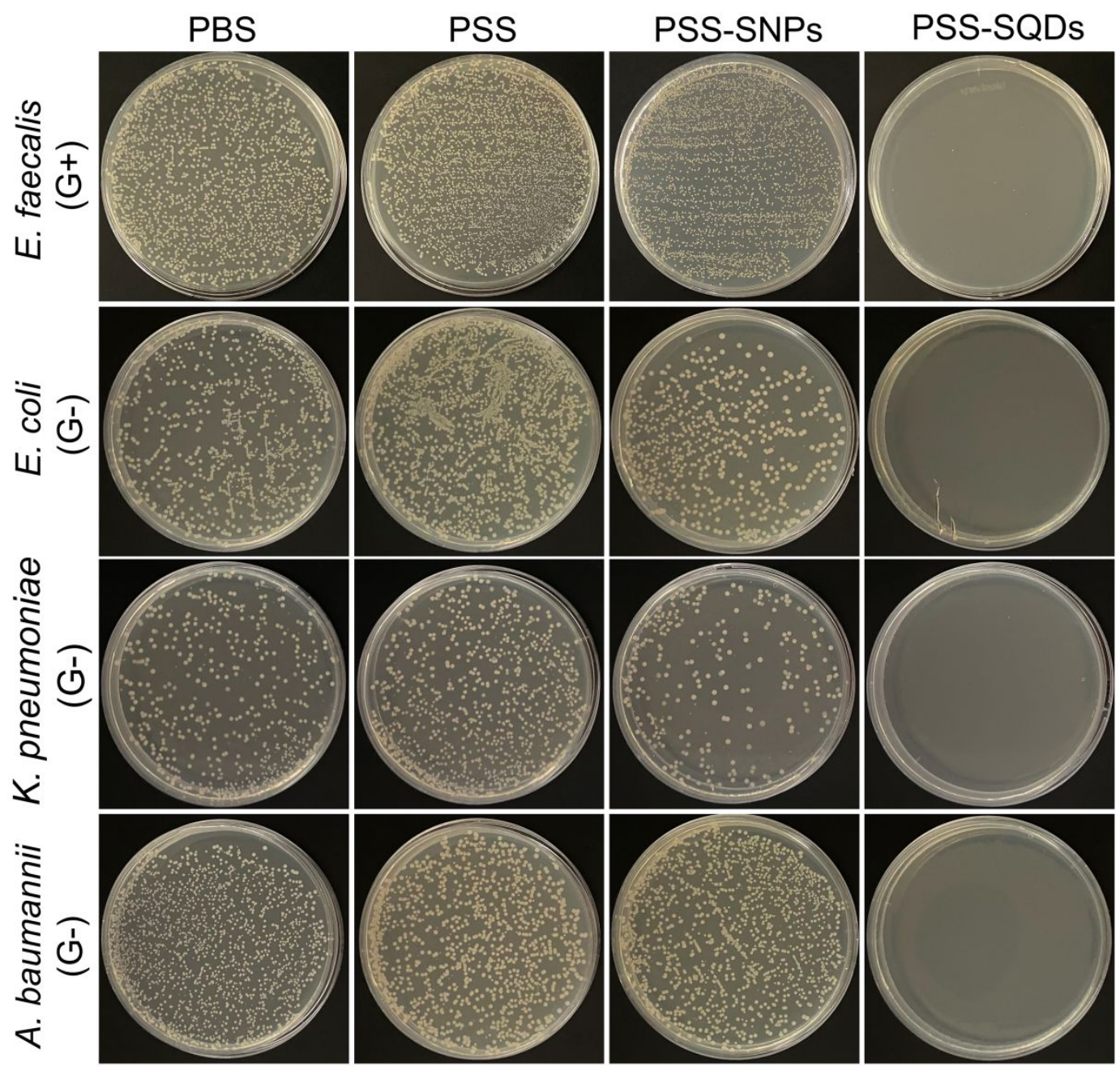

Figure S22. Antibacterial performance of PSS-SQDs on other pathogenic bacteria. The $E$. faecalis, E. coli, K. pneumoniae, A. baumannii were treated with PBS buffer (0.01M, pH 7.4), PSS, PSS-SNPs, and PSS-SQDs and grown on LB agar, respectively. The concentration of PSS, PSS-SNPs, PSS-SQDs were all $1.2 \mathrm{mg} / \mathrm{mL}$. “G+" represents Gram-positive bacteria, “G-" represents Gram-negative bacteria. 

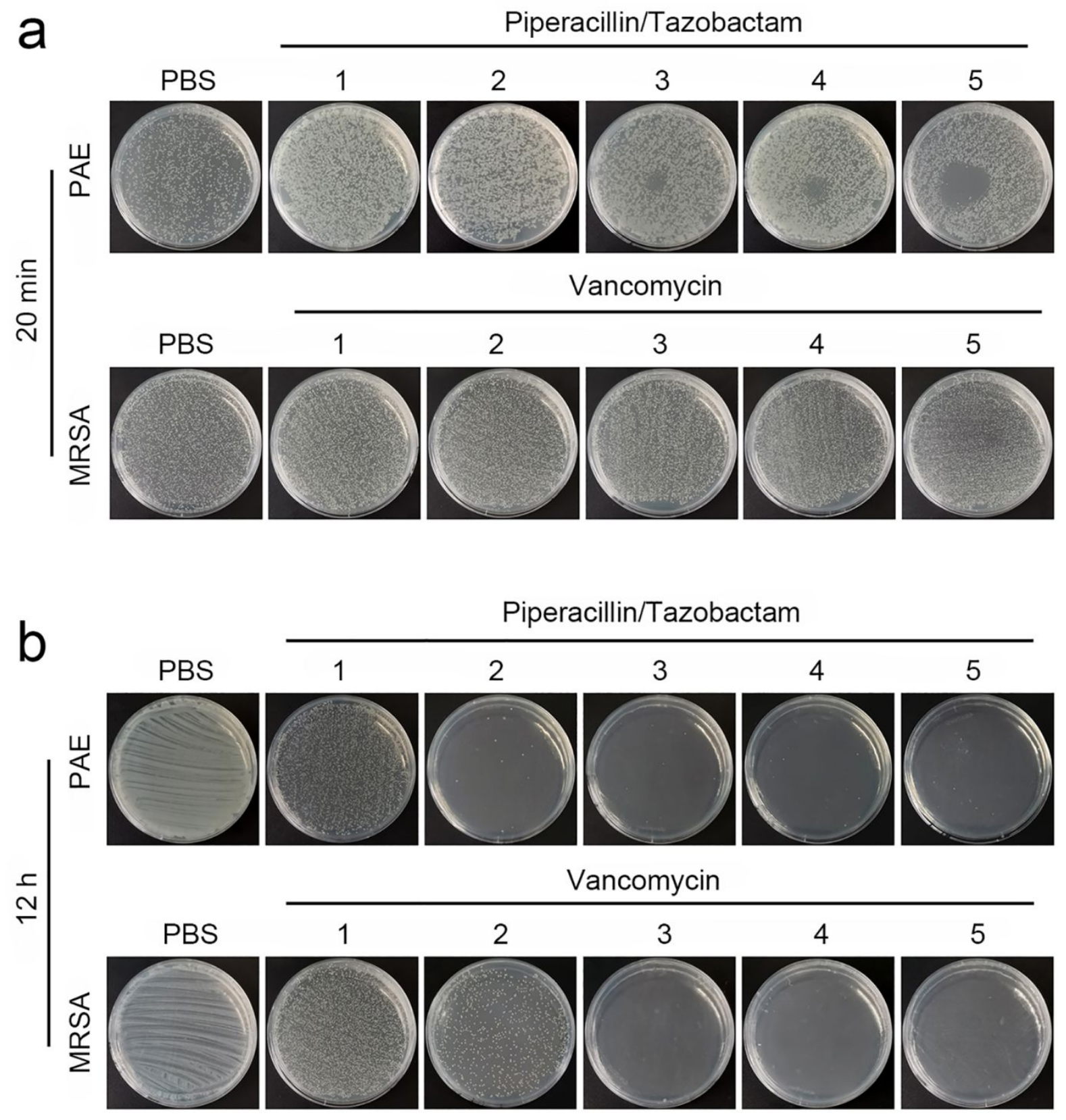

Figure S23. Bacteriostatic effects of different concentrations of piperacillin/tazobactam and vancomycin on PAE and MRSA, respectively. The bacteria were incubated with the drugs for (a) 20 min and (b) $12 \mathrm{~h}$, respectively, and then cultivated on the LB agar. The concentrations of piperacillin/tazobactam (No. 1-5) were 16, 32, 64, 128, and $256 \mu \mathrm{g} / \mathrm{mL}$. The concentrations of vancomycin (No. 1-5) were $1,2,4,8$, and $16 \mu \mathrm{g} / \mathrm{mL}$. 


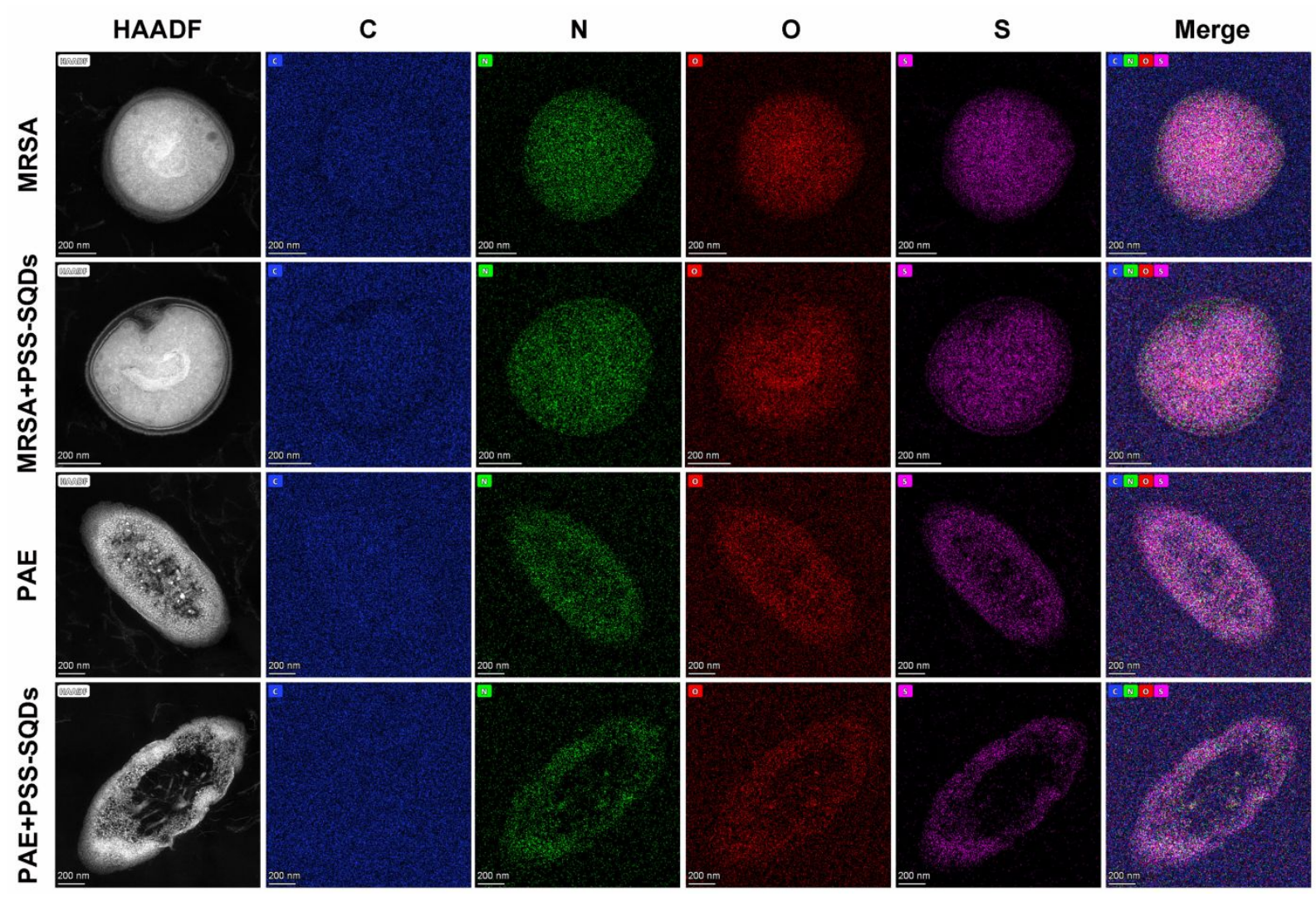

Figure S24. High-angle annular dark-field (HAADF) imaging and elemental mapping results of the bacteria before and after the interaction with PSS-SQDs. The distribution of carbon element is not obvious because the substrate for loading bacterial samples is carbon supporting membrane. 

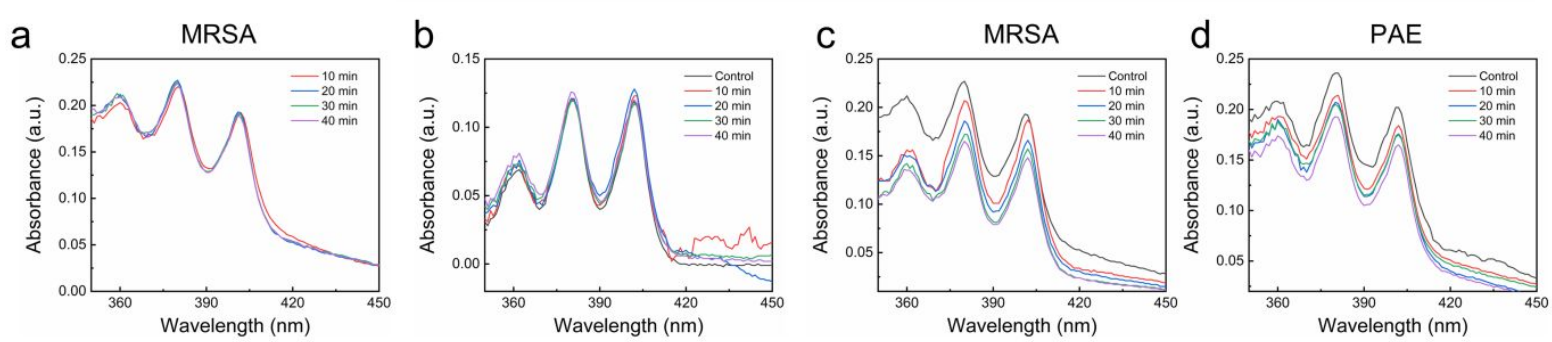

PSS-SNPS
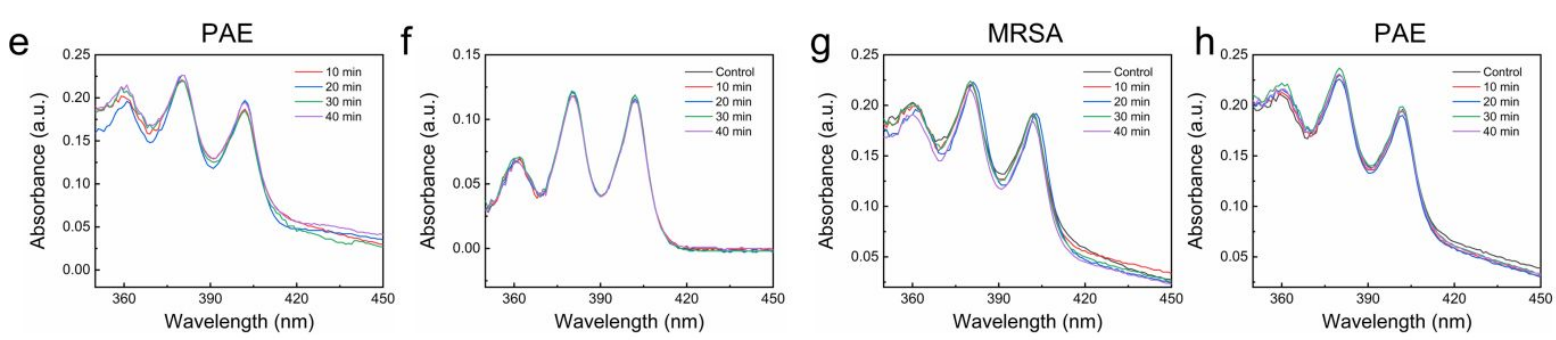

Figure S25. Generation of ROS verified by monitoring the absorbance decrease of ABDA at $378 \mathrm{~nm}$ along with time increase. The abilities of ROS generation of PSS-SQDs (b-d) and PSS-SNPs (f-h) were both studied. (a) the mixture of ABDA and MRSA; (b) the mixture of ABDA and PSS-SQDs; (c) the mixture of ABDA, PSS-SQDs, and MRSA; (d) the mixture of ABDA, PSS-SQDs, and PAE; (e) the mixture of ABDA and PAE; (f) the mixture of ABDA and PSS-SNPs; (g) the mixture of ABDA, PSS-SNPs, and MRSA; (h) the mixture of ABDA, PSS-SNPs, and PAE. The control line in each figure represents the absorption spectrum of pure ABDA. 
a

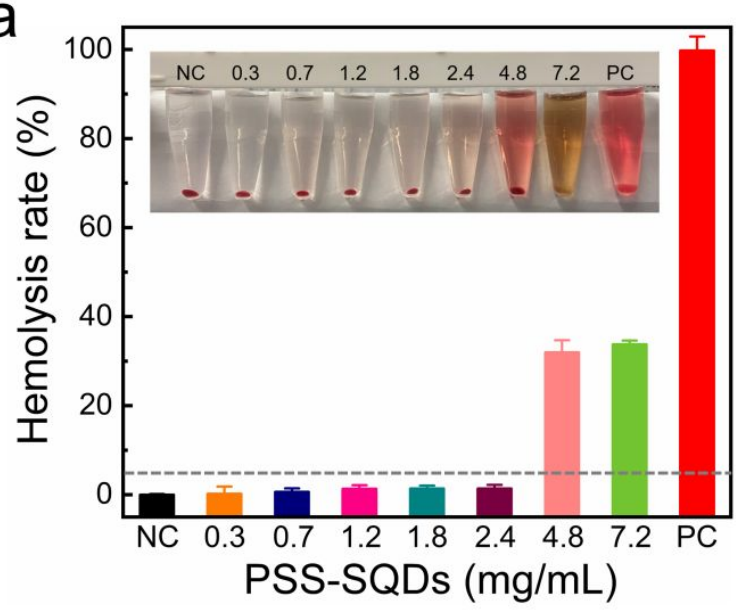

C

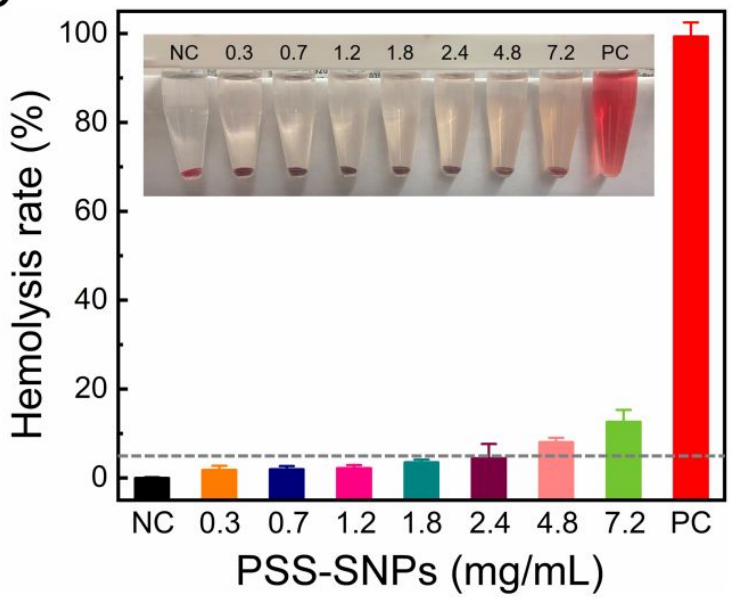

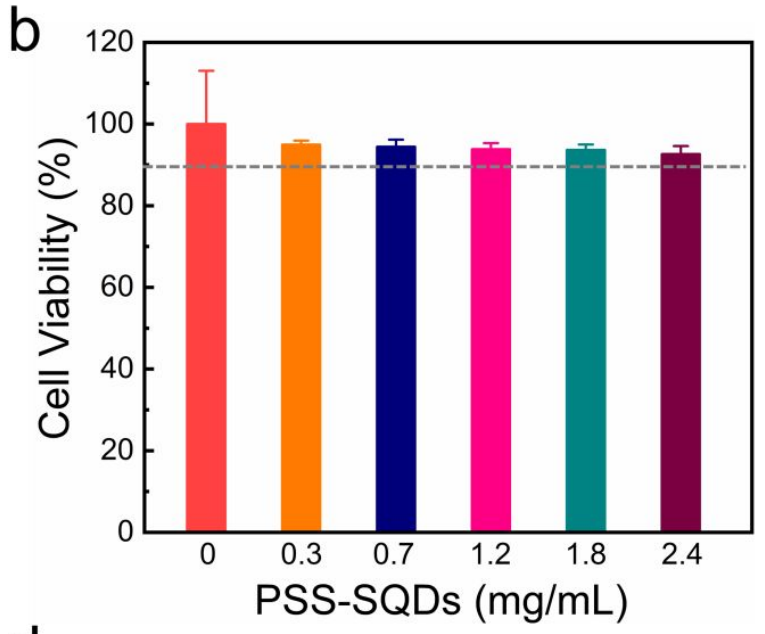

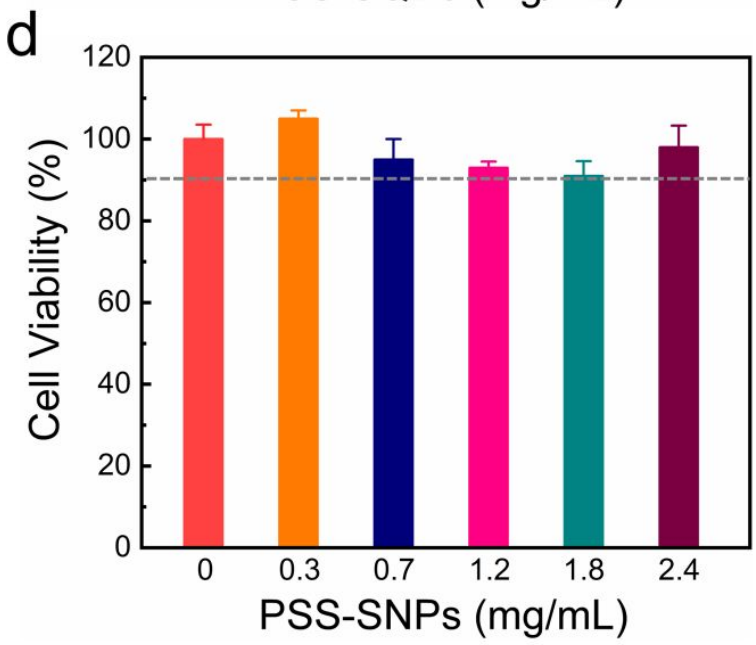

Figure S26. Biocompatibility evaluation of PSS-SQDs and PSS-SNPs. (a, c) Hemolysis rate of red blood cells after treated with different concentrations of PSS-SQDs and PSS-SNPs, respectively. $\mathrm{NC}$ refers to negative control (with $0.9 \% \mathrm{NaCl}$ ), and $\mathrm{PC}$ refers to positive control (with $\mathrm{H}_{2} \mathrm{O}$ ). (b, d) Cytotoxicity of PSS-SQDs and PSS-SNPs with different concentrations against HUVEC by MTS assay. 
MRSA

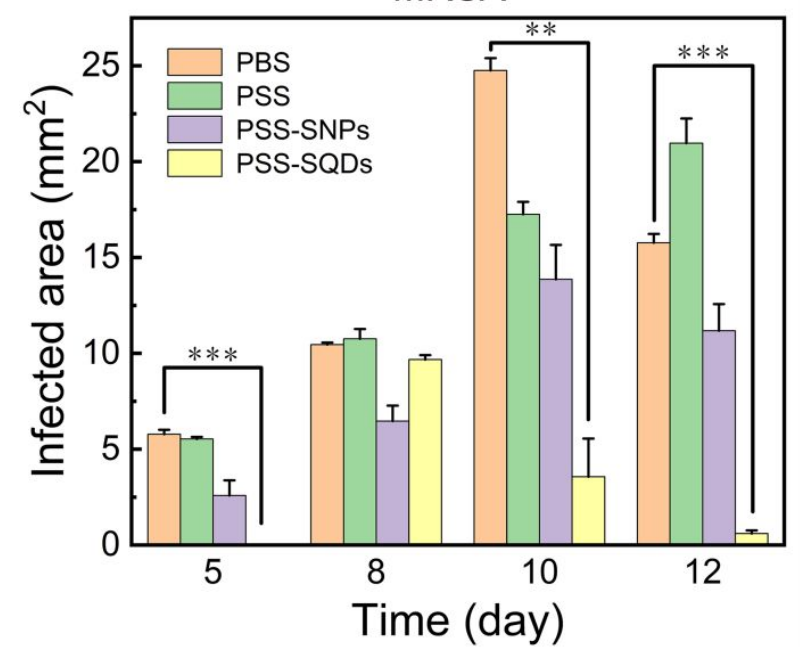

PAE

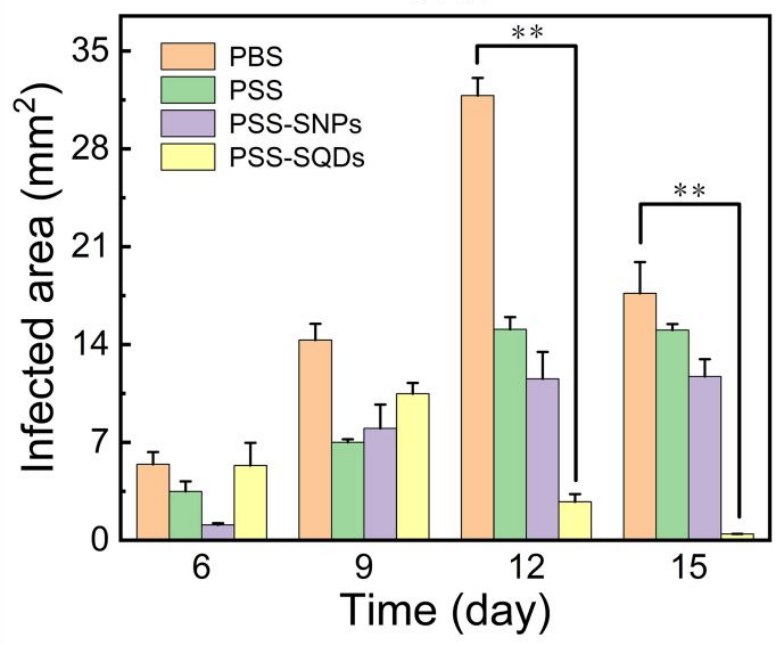

Figure S27. Infected areas of the wound in each group measured at different time during the treatment of MRSA- and PAE-infected mice, respectively. Error bars represent the standard deviation of three parallel tests. Asterisks indicate significant differences $\left({ }^{*} p<0.05,{ }^{* *} p<\right.$ $0.01, * * * p<0.001)$. 

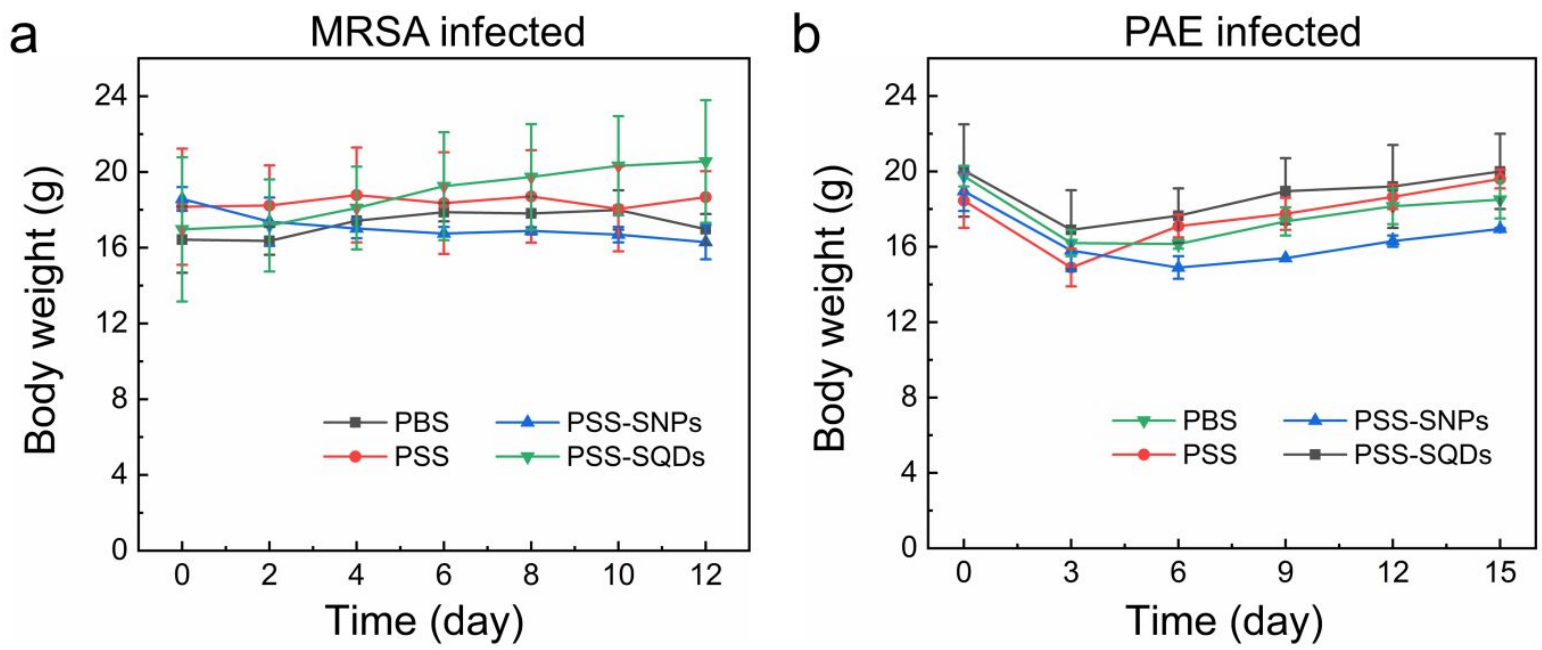

Figure S28. Body weights of (a) MRSA-infected and (b) PAE-infected mice during the whole therapy period under different treatments. Error bars represent the standard deviation of three parallel samples. 